\title{
Estudo do componente arbóreo de dois trechos da Floresta Ombrófila Densa Submontana em Ubatuba (SP)
}

\author{
Eliana Ramos ${ }^{1,4}$, Roseli Buzanelli Torres ${ }^{2}$, Renato Ferraz de Arruda Veiga ${ }^{2}$ \& Carlos Alfredo Joly ${ }^{3}$ \\ ${ }^{1}$ Programa de Pós-Graduação em Ciências Biológicas (Biologia Vegetal), Instituto de Biociências, \\ Universidade Estadual Paulista Júlio de Mesquita Filho - UNESP, \\ CP 199, CEP 13506-900, Rio Claro, SP, Brasil \\ ${ }^{2}$ Núcleo de Pesquisa e Desenvolvimento Jardim Botânico, Centro de Recursos Genéticos Vegetais - IAC, \\ Av. Barão de Itapura, 1481, CEP 13020-902, Campinas, SP, Brasil \\ ${ }^{3}$ Departamento de Biologia Vegetal, Instituto de Biologia, \\ Universidade Estadual de Campinas - UNICAMP, \\ CP 6109, CEP 13083-970, Campinas, SP, Brasil \\ ${ }^{4}$ Autor para correspondência: Eliana Ramos, e-mail: elianaramos.bio@gmail.com
}

RAMOS, E; TORRES, R.B.; VEIGA, R.F.A. \& JOLY, C.A. Study of the arboreal component in two areas of the Submontane Rainforest in Ubatuba, São Paulo State. Biota Neotrop. 11(2): http://www.biotaneotropica. org.br/v11n2/en/abstract?inventory+bn02411022011

\begin{abstract}
We studied the floristic composition and structure of the arboreal component (trees, palms and ferns with DBH equal to or greater than $4.8 \mathrm{~cm}$ ) of two plots of Lower Montane Rain Forest in Ubatuba, SP, one with a history of selective logging and the other more preserved. We sampled 50 families, 114 genera and 193 species (four undetermined). The richest families were Myrtaceae, Fabaceae, Lauraceae, Rubiaceae, Melastomataceae and Sapotaceae. In the disturbed plot we sampled 104 species, 72 genera and 39 families, and in the more preserved area, 152 species, 98 genera and 43 families. There were differences in species richness, in the prevalence of their succesional status and in the structure of the areas, and the multivariate analysis allowed recognition of two floristic blocks. Among all species, 33 were exclusive of the first plot and 95 were exclusive of the second plot. Almost half of the species (45\%) occurred with only one or two individuals and 29 have some degree of rarity. Five species are in the category of vulnerable in the List of brazilian plant species threatened of extinction. The differences observed between the sites studied, as well as the occurrence of rare and endangered species highlight the importance of the conservation of the area.
\end{abstract}

Keywords: Atlantic Rainforest, anthropic disturbance, Serra do Mar State Park, Capricórnio Farm, rare species.

RAMOS, E; TORRES, R.B.; VEIGA, R.F.A. \& JOLY, C.A. Estudo do componente arbóreo de trechos da Floresta Ombrófila Densa Submontana em Ubatuba (SP). Biota Neotrop. 11(2): http://www.biotaneotropica. org.br/v11n2/pt/abstract?inventory+bn02411022011

Resumo: Neste trabalho foram analisadas a composição florística e a estrutura do componente arbóreo (árvores, palmeiras e fetos arborescentes com DAP igual ou maior que $4,8 \mathrm{~cm}$ ) de dois trechos de Floresta Ombrófila Densa Submontana, em Ubatuba, SP, um deles com histórico de extração seletiva de madeira e o outro mais preservado. Foram amostradas 50 famílias, 114 gêneros e 193 espécies (quatro indeterminadas). As famílias mais ricas foram Myrtaceae, Fabaceae, Lauraceae, Rubiaceae, Melastomataceae e Sapotaceae. No trecho mais perturbado foram amostrados 104 espécies, 72 gêneros e 39 famílias e no mais preservado, 152 espécies, 98 gêneros e 43 famílias. Foram observadas diferenças na riqueza de espécies, na prevalência de suas categorias sucessionais e na estrutura das áreas, e as análises multivariadas permitiram o reconhecimento de dois blocos florísticos. Do total de espécies, 33 foram exclusivas do primeiro trecho e 95 do segundo. Quase metade das espécies (45\%) ocorreram com apenas um ou dois indivíduos e 29 apresentam algum grau de raridade. Cinco espécies são vulneráveis segundo a Lista oficial das espécies da flora brasileira ameaçadas de extinção. As diferenças observadas entre os trechos estudados, bem como a ocorrência de espécies raras e ameaçadas de extinção evidenciam a importância da conservação da área. Palavras-chave: Mata Atlântica, perturbação antrópica, Parque Estadual da Serra da Mar, Fazenda Capricórnio, espécies raras. 


\section{Introdução}

A Mata Atlântica é um dos hotspots (Myers et al. 2000) mais devastados e ameaçados do planeta (Galindo-Leal \& Câmara 2005). No Estado de São Paulo a maior parte da atividade econômica paulista está concentrada em áreas de domínio deste bioma (Food... 2006, Jenkins \& Pimm 2006), e os remanescentes florestais mais expressivos estão localizados nas áreas de encosta, atualmente associadas a unidades de conservação como o Parque Estadual da Serra do Mar (PESM), onde há ameaça constante devida a fatores como pressão urbana, implantação de infra-estrutura básica e de desenvolvimento regional, turismo desordenado, extrativismo e caça sistemática, e ocupação por migrantes (São Paulo 2008, Instituto... 2006). Mesmo em uma área protegida, como o PESM, ocorre degradação e perda de habitats e espécies devidas à diminuição de suas áreas de ocorrência (Whitmore 1990; Silva \& Casteleti 2005; Hegerl et al. 2007), uma amostra em menor escala do que aconteceu com o estado de São Paulo como um todo, que teve sua cobertura florestal drasticamente reduzida (Kronka et al. 2005).

Neste trabalho a composição florística e a estrutura horizontal do componente arbóreo de dois trechos de Floresta Ombrófila Densa Submontana foram analisadas na Fazenda Capricórnio, Parque Estadual da Serra do Mar (PESM), no município de Ubatuba (SP), com o propósito de: 1) listar as espécies da flora arbórea; 2) comparar a florística e a estrutura dos trechos entre si; e 3) identificar espécies raras ou ameçadas de extinção.

\section{Material e Métodos}

\section{Caracterização da área}

O estudo foi realizado no município de Ubatuba nas terras da Fazenda Capricórnio, propriedade particular com cerca de 1.220 ha. A área é uma das selecionadas para a realização dos estudos florísticos e fitossociológicos do projeto temático Biota Gradiente Funcional (Joly et al. 2011). Os trechos estudados

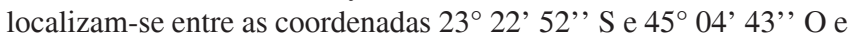
entre $23^{\circ} 22^{\prime} 25^{\prime \prime} \mathrm{S}$ e $45^{\circ} 04^{\prime}$ 53" O e, segundo Veloso et al. (1991), enquadram-se na categoria de Floresta Ombrófila Densa Submontana.

A primeira das duas parcelas estudadas (parcela F) abrange áreas que variam dos 80 aos $120 \mathrm{~m}$ de altitude, na Fazenda Capricórnio. Alguns locais apresentam grandes clareiras e trepadeiras ocorrem com freqüência, assim como espécies de sub-bosque e abundância de epífitas. Aproximadamente a $900 \mathrm{~m}$ de distância fica a outra parcela (parcela H), que localiza-se dos 200 aos $216 \mathrm{~m}$ de altitude (Parque Estadual da Serra do Mar), apresenta menos clareiras e menos trepadeiras que o trecho anterior e é levemente mais íngreme. Também ocorrem muitas espécies de sub-bosque e maior abundância de epífitas.

Parte da fazenda, nas menores altitudes, já foi utilizada para a cultura de cacau, com início em 1971. A atividade cacaueira cessou mas os cacaueiros, além das árvores emergentes preservadas na época, foram mantidos, e no local estabeleceu-se vegetação de sub-bosque. Funcionários antigos relatam que as árvores de maior diâmetro com potencial madeireiro foram retiradas para uso e comercialização, sendo a madeira processada em serraria da própria fazenda. A atividade madeireira ocorreu principalmente na parcela $\mathrm{F}$, mais acessível devido à altitude, e onde há evidências dessa atividade. Nas partes mais altas, a extração também ocorreu, porém de forma mais discreta. A exploração de árvores na fazenda cessou em 1982, embora a serraria tenha continuado com suas atividades por mais algum tempo. Atualmente, a Fazenda Capricórnio é considerada um dos pontos turísticos do município de Ubatuba e recebe visitação esporádica de turistas e escolas (sr. Salvador dos Santos, informação pessoal). Há décadas essas matas são alvo de palmiteiros e caçadores, que até hoje exploram a área clandestinamente.

\section{Coleta de material botânico e identificação das espécies}

O levantamento florístico foi realizado a partir da coleta de material botânico dos indivíduos arbóreos, incluindo palmeiras e fetos arborescentes. A definição das parcelas, os critérios de inclusão, a coleta e identificação do material botânico estão descritos em Joly et al. (2011). As viagens de coleta foram realizadas no período de setembro de 2006 a setembro de 2007 para a parcela F e no período de fevereiro de 2007 a junho de 2008 para a parcela $\mathrm{H}$.

Os procedimentos na identificação do material botânico, distribuição das espécies por famílias e distribuição do material testemunho estão descritas em Joly et al. (2011). Os nomes populares das espécies foram anotados e o material, depois de montado e registrado, foi fotografado para ilustrar uma chave de identificação a partir de caracteres vegetativos.

\section{Análises}

Para as análises fitossociológicas os parâmetros utilizados estão descritos em Joly et al. (2011). Para as análises multivariadas foi utilizado o programa FITOPAC 2.0 (Shepherd 2009), e foram calculados os índices de diversidade de Shannon (H') e de eqüabilidade de Pielou (J) (Pielou 1975, Magurran 2004), além de outros parâmetros fitossociológicos usuais, e foram geradas matrizes de ocorrência e de abundância das espécies amostradas em cada parcela, para as análises multivariadas. A diversidade de Shannon $\left(\mathrm{H}^{\prime}\right)$ dos dois trechos foi comparada por meio do teste $t$ modificado, descrito por Poole (1974), utilizando o software PAST versão 1.79 (Hammer et al. 2001), com nível de significância $(\alpha)$ de $5 \%$, e a diversidade entre as áreas foi comparada por meio do teste Mann-Whitney (Zar 1999), uma vez que os dados mostraram-se não-paramétricos após teste da normalidade dos dados (D'Agostino-Pearson, $\alpha=5 \%$ ), transformação logarítimica em $\log ^{10}$ e remoção dos valores extremos (outliers) apontados com base nos quartis (Zar 1999).

A área basal dos trechos foi comparada por meio do teste $t$ (Zar 1999), após teste de normalidade dos dados (D’AgostinoPearson, $\alpha=5 \%$ ), extração dos valores extremos (outliers) apontados com base nos quartis (Zar 1999), e emprego do teste R versão 2.9, que apontou a homocedasticidade ou homogeneidade de variância dos dados (Zar 1999). Para seguir com as análises multivariadas, foram verificados os outliers e eliminadas nove parcelas tanto da matriz florística binária, quanto da matriz quantitativa (McCune \& Mefford 1999). Utilizamos o software PC-ORD versão 4.0 (McCune \& Mefford 1999) adotando-se o nível de corte de 2.0 (default). Uma análise de agrupamento (cluster) pelo método de média de grupo, UPGMA (Sneath \& Sokal 1973) foi efetuada a fim de verificar a similaridade florística entre as parcelas. O coeficiente de Jaccard, que exclui a dupla-ausência (0/0), foi empregado. Para a matriz quantitativa, optou-se pelo coeficiente de distância de Bray-Curtis. A Análise de Coordenadas Principais (PCO) foi empregada no FITOPAC 2.0 como método de ordenação, utilizando-se o coeficiente de Jaccard, utilizado na UPGMA. Através da análise TWINSPAN - Two-Way-Indicator-Species-Analysis - foram obtidas as espécies indicadoras para os grupos gerados (Gauch Junior 1982), tanto a partir de dados de presença e ausência das espécies quanto de abundância de indivíduos.

As categorias sucessionais foram consultadas em Brandão et al. (2009), Cardoso-Leite \& Rodrigues (2008), Catharino et al. (2006), Dias Neto et al. (2009), Mantovani et al. (2005), Neves \& Peixoto (2008), Pinto et al. (2005), Sanchez et al. (1999), Santos et al. (2006), Schorn \& Galvão (2006) e na Resolução SMA 08 de 31 de janeiro 
de 2008/Anexo (São Paulo 2008). Os biomas de ocorrência das espécies e endemismo foram indicados segundo Forzza et al. (2010); as fisionomias segundo a Resolução SMA 08 de 31 de janeiro de 2008 e Barbosa et al. (2009). As categorias de ameaça foram consultadas na Lista oficial das espécies da flora brasileira ameaçadas de extinção (Brasil 2008) e na revisão da Biodiversitas (2010). Não foram consideradas as espécies indeterminadas ou identificadas apenas ao nível de gênero.

A raridade das espécies ocorrentes nos dois trechos foi determinada com base nos critérios propostos por Rabinowitz et al. (1986), que sugerem oito categorias de raridade, onde as espécies podem ser classificadas quanto: 1) ao tamanho da população; 2) à distribuição geográfica; e 3) à especificidade de hábitat. Segundo o conceito de Moreira (2007), que define quatro grupos de densidade, as espécies foram consideradas ocasionais, quando ocorrem com apenas um indivíduo por hectare; comuns, com dois a 10 indivíduos por hectare; constantes, com 11 a 100 indivíduos, e abundantes, com mais de 100. Os resultados foram comparados com outros trabalhos de mesma fisionomia (Campos 2008; Ivanauskas 1997; Lacerda 2001; Silva \& Leitão Filho 1982) e com o de Caiafa \& Martins (2010), que consideraram um conjunto maior de dados para a Mata Atlântica.

\section{Resultados}

Foram amostradas no total 193 espécies (Tabela 1) pertencentes a 50 famílias. Na parcela $\mathrm{F}$ foram amostradas 104 espécies, pertencentes a 72 gêneros e 39 famílias. Na parcela $\mathrm{H}$ foram amostradas 152 espécies, 98 gêneros e 44 famílias. Do total de espécies amostrado, 67 espécies são comuns às duas áreas, o que equivale a $34,7 \%$. Apesar da proximidade entre os trechos, houve diferença em relação às espécies encontradas - 33 espécies ocorreram com exclusividade no primeiro trecho e 95 somente no segundo.

Na parcela $\mathrm{F}$ as famílias mais ricas são Myrtaceae (oito gêneros, 17 espécies), Fabaceae (sete, oito), Lauraceae (seis, sete), Rubiaceae (cinco, sete) e Melastomataceae (três, seis), totalizando 29 gêneros e 45 espécies (43,2\% do total de espécies do trecho). Os gêneros mais ricos são Eugenia (com seis espécies), seguido de Alchornea, Ocotea, Miconia, Ficus, Marlierea, Piper e Solanum, todos com três espécies cada, totalizando 27 espécies, ou $26 \%$ do total. Na parcela $\mathrm{H}$ destacam-se Rubiaceae (11 gêneros, 18 espécies), Fabaceae (10, 13), Myrtaceae (oito, 32), Sapotaceae (quatro, oito) e Lauraceae e Melastomaceae (quatro, sete), totalizando 41 gêneros e 85 espécies ( $56 \%$ do total), evidenciando que este é o trecho mais rico. Os gêneros mais ricos são Eugenia, com 15 espécies, seguido de Marlierea, Mollinedia e Pouteria (cinco), Miconia e Myrcia (quatro), além de Bathysa, Calyptranthes, Cupania, Guapira, Inga, Maytenus, Ocotea, e Psychotria, todos com três espécies cada, totalizando 62 espécies, ou $40,8 \%$ do total.

Dentre o material enviado aos especialistas para identificação foram apontadas duas espécies possivelmente novas para a ciência: Eugenia sp. e Miconia sp., ressaltando a importância de estudos florísticos no conhecimento e caracterização de remanescentes florestais, e evidenciando a necessidade de se preservar áreas como estas que, apesar dos estudos já existentes, ainda abrigam espécies desconhecidas. Foi elaborada uma chave de identificação, com base em caracteres vegetativos, para as 193 espécies amostradas (Eltink et al. 2011), que também encontra-se on line (Eltink 2009).

A Tabela 2 apresenta os parâmetros fitossociológicos para a parcela $\mathrm{F}$, onde amostraram-se 1.379 indivíduos, sendo 88,2\% árvores, $10 \%$ fetos arborescentes, 1,8\% palmeiras e 1,9\% árvores mortas em pé. A Tabela 3 apresenta os parâmetros fitossociológicos para a parcela $\mathrm{H}$, onde ocorreram 1.528 indivíduos, sendo que $86,4 \%$ correspondem a árvores, $13,2 \%$ são palmeiras, $0,4 \%$ fetos arborescentes e 4,5\% árvores mortas em pé. No trecho mais baixo a família mais abundante é Rubiaceae, seguida por Fabaceae, Myrtaceae e Cyatheaceae. No trecho mais alto a família mais abundante também é Rubiaceae, seguida por Myrtaceae, Arecaceae e Monimiaceae. Estas famílias também se destacaram pela abundância ou riqueza em outros estudos em fisionomias de floresta ombrófila densa (Silva \& Leitão Filho 1982, Sanchez et al. 1999, Kurtz \& Araújo 2000, Lacerda 2001, Moreno et al. 2003, Guedes-Bruni et al. 2006), com exceção de Cyatheaceae.

Na parcela $\mathrm{F}$ as famílias mais importantes são Rubiaceae, Fabaceae, Myrtaceae, Cyatheaceae e Phyllantaceae. Myrtaceae é a única cujos VI e VC deve-se a um número maior de espécies. O VI e o VC das outras famílias deve-se à grande abundância de Bathysa australis (83,5\% do total de indivíduos de Rubiaceae), Lonchocarpus cultratus (86\% das Fabaceae), Alsophylla sternbergii (75\% de Cyatheaceae) e Hyeronima alchorneoides (100\% de Phyllantaceae). Juntas, Rubiaceae, Fabaceae, Myrtaceae e Cyatheaceae representam $51 \%$ do total de indivíduos amostrados. As 10 famílias mais abundantes representam $76 \%$ do total de indivíduos. Os valores resultam principalmente das densidades populacionais de Bathysa australis, Lonchocarpus cultratus, Eugenia aff. oblongata e Myrceugenia myrcioides, Alsophila sternbergii, Alchornea glandulosa e A. triplinervea, Guapira opposita, Hyeronima alchorneoides, Mollinedia schottiana, Ocotea dispersa e O. paranapiacabensis. Dezesseis famílias e 53 gêneros são representados por uma única espécie, e 31 espécies por um indivíduo, sendo 16 delas pertencentes a gêneros que ocorreram com uma única espécie.

$\mathrm{Na}$ parcela $\mathrm{H}$ as famílias mais importantes são Myrtaceae, Rubiaceae, Arecaceae e Sapotaceae. Os maiores VIs são de Rudgea jasminoides (37\% do total de indivíduos de Rubiaceae) e Euterpe edulis (71\% de Myrtaceae) e os maiores VCs são de Rudgea jasminoides, Eriotheca pentaphylla, Euterpe edulis, Guapira opposita e Mollinedia schottiana. Neste trecho os VI e VC de Myrtaceae também devem-se a um grande número de espécies. Rubiaceae, Arecaceae, Myrtaceae e Monimiaceae representam 60\% do total de indivíduos. As 10 famílias mais abundantes representam $78,5 \%$ do total de indivíduos e as espécies que mais contribuem para este resultado são Rudgea jasminoides, Coussarea accedens e C. meridionalis var. porophylla, Bathysa australis e B. mendoncaei, Eugenia oblongata, E. prasina, Marlierea sp. e Myrciaria floribunda, Euterpe edulis e Syagrus pseudococos, Mollinedia schottiana, Chrysophyllum flexuosum, Guapira opposita, Ardisia martiana, Eriotheca pentaphylla, Dahlstedtia pinnata e Cryptocarya mandioccana. Quatro famílias - Aquifoliaceae, Burseraceae, Magnoliaceae e Salicaceae - e 78 gêneros são representadas por uma única espécie e 41 espécies são representadas por apenas um indivíduo. Destas, 20 pertencem aos gêneros que oocorreram com uma só espécie na área.

Dentre as famílias mais abundantes nas duas parcelas, seis são comuns entre elas: Rubiaceae, Myrtaceae, Monimiaceae, Nyctaginaceae, Fabaceae e Lauraceae. Estes números conferem diversidade às áreas, principalmente à parcela $\mathrm{H}$. Para os dois trechos a abundância das famílias difere tanto em número quanto em ordenação para a maioria delas (Figura 1).

Embora as famílias mais abundantes sejam as mesmas apontadas para outros estudos de Floresta Ombrófila Densa, Bathysa autralis, Alsophila sternbergii e Lonchocarpus cultratus destacam-se pela grande abundância na parcela $\mathrm{F}$, diferindo dos resultados de outros trabalhos, nos quais estas espécies ocorreram com menos indivíduos (Silva \& Leitão Filho 1982, Kurtz \& Araújo 2000, Lacerda 2001, Moreno et al. 2003, Guedes-Bruni et al. 2006). Estas espécies respondem praticamente sozinhas pela importância de suas respectivas famílias, e somam $34,6 \%$ do total de indivíduos. $\mathrm{Na}$ 
Tabela 1. Árvores, palmeiras e fetos arborescentes com pelo menos $15 \mathrm{~cm}$ de perímetro amostradas aos $100 \mathrm{~m}$ e aos $200 \mathrm{~m}$ de altitude na Fazenda Capricórnio, Ubatuba, PESM (SP), nomes populares e número de registro das coletas incorporadas no herbário IAC. Legenda: Categoria sucessional: $\mathrm{P}=$ pioneira; SI = secundária inicial; ST = secundária tardia; $\mathrm{C}=$ clímax; $\mathrm{NP}=$ não pioneira; $\mathrm{NC}=$ não classificada; Graus de raridade $($ Moreira 2007): oc $=$ ocasional (1 indivíduo); co = comum (2-10 ind.); cs = constante (11-100 ind.); ab = abundante (+ 100 ind.); Graus de raridade (Caiafa \& Martins 2010): cm (comum); Graus de ameaça: VU = vulnerável; EN = Em perigo; $\mathrm{CR}=$ criticamente em perigo; $(*)$ segundo Lista da flora brasileira ameaçada de extinção; $(* *)$ segundo Revisão da Biodiversitas; Ambiente de Ocorrência: $\mathrm{AMA}=$ amazônia; $\mathrm{CAA}=$ caatinga; $\mathrm{CER}=$ cerrado; $\mathrm{MA}=$ mata atlântica RES = restinga; FOD = floresta ombrófila densa; FOM = floresta ombrófila mista; FES = floresta estacional semidecídua; FED = floresta estacional decídua; $\mathrm{PAM}=$ pampa; $\mathrm{PAN}=$ pantanal .

Table 1. Trees, palms and ferns with at least $15 \mathrm{~cm}$ of perimeter sampled at $100 \mathrm{~m}$ and $200 \mathrm{~m}$ above sea level in Capricórnio Farm, Ubatuba, PESM (SP), common names and the registered number in IAC herbarium. Caption: Category of succession: $\mathrm{P}=$ pioneer, early secondary $=\mathrm{SI}$; late secondary ST; C = climax, $\mathrm{NP}=$ not a pioneer, $\mathrm{NC}=$ not classified; Degrees of rarity (Moreira 2007): oc $=$ occasional (one individual); $\operatorname{co}=\mathrm{common}(2-10 \mathrm{ind}$.); $\mathrm{cs}=\mathrm{Constant}$ (11-100 ind.); $\mathrm{ab}=$ abundant $(100+$ ind.); Degrees of rarity (Caiafa \& Martins 2010$)$ : $\mathrm{cm}($ common ); Degree of threat: VU = vulnerable, EN = Endangered, $\mathrm{CR}=$ critically endangered; $(*)$ second list of endangered flora, $(* *)$ the second review of Biodiversity, Environmental Occurrence: $\mathrm{AMA}=\mathrm{Amazon}$; $\mathrm{CAA}=$ savanna; $\mathrm{CER}=$ savanna; $\mathrm{MA}=$ rainforest; res = sandbank; FOD = dense rain forest; FOM = Araucaria forest FES = semideciduous; $\mathrm{EDF}=$ deciduous forest; MAP = pampa; PAN $=$ Pantanal Wetland.

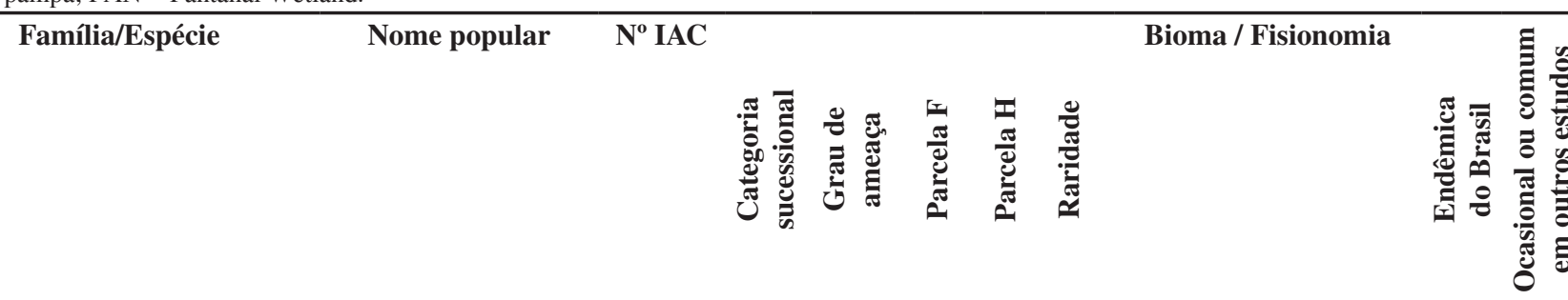

\begin{tabular}{|c|c|c|c|c|c|c|c|c|c|c|}
\hline Annonaceae & & & & & & & & & & \\
\hline Guatteria australis A.St.-Hil. & & 49218 & ST & & oc & co & $\mathrm{cm}$ & MA (RES/FOD/FES) & $\mathrm{X}$ & $\mathrm{X}$ \\
\hline $\begin{array}{l}\text { Rollinia dolabripetala (Raddi) } \\
\text { R.E.Fr. } \\
\text { Apocynaceae }\end{array}$ & araticum & 49168 & SI & & cs & oc & & $\mathrm{MA}(\mathrm{FOD})$ & $\mathrm{X}$ & \\
\hline $\begin{array}{l}\text { Malouetia arborea (Vell.) Miers } \\
\text { Aquifoliaceae }\end{array}$ & & 49769 & $\mathrm{P}$ & & - & co & 4 & FES/FOD & & \\
\hline Ilex theezans Mart. ex Reissek & & 50552 & $\mathrm{P}$ & & co & $\mathrm{oc}$ & $\mathrm{cm}$ & $\begin{array}{l}\text { AMA/CAA/CER/MA } \\
\text { (RES/FOD/FOM) }\end{array}$ & $\mathrm{X}$ & $\mathrm{X}$ \\
\hline Araliaceae & & & & & & & & & & \\
\hline $\begin{array}{l}\text { Dendropanax cuneatus (DC.) } \\
\text { Decne. \& Planch. }\end{array}$ & mandioqueiro & 49273 & $\mathrm{C}$ & & oc & - & 4 & $\begin{array}{l}\text { AMA/CAA/CER/MA } \\
\text { (FOD)/PAN }\end{array}$ & & $\mathrm{X}$ \\
\hline $\begin{array}{l}\text { Schefflera angustissima } \\
\text { (Marchal) Frodin }\end{array}$ & embirutó-branco & 49113 & SI & & $\mathrm{oc}$ & co & - & MA (RES/FOD) & $\mathrm{X}$ & \\
\hline $\begin{array}{l}\text { Schefflera calva (Cham.) } \\
\text { Frodin \& Fiaschi } \\
\text { Arecaceae }\end{array}$ & embirutó-vermelho & 49190 & $\mathrm{P}$ & & oc & co & 4 & $\begin{array}{l}\text { CER/MA (RES/FOD/ } \\
\text { FOM/FES) }\end{array}$ & $\mathrm{X}$ & $\mathrm{X}$ \\
\hline $\begin{array}{l}\text { Astrocaryum aculeatissimum } \\
\text { (Schott) Burret }\end{array}$ & brejaúva & 51963 & SI & & - & co & 4 & MA (RES/FOD) & $\mathrm{X}$ & \\
\hline Euterpe edulis Mart. & palmito & 49271 & ST & VU* & cs & $a b$ & $\mathrm{~cm}$ & CER/MA (FOD) & & \\
\hline $\begin{array}{l}\text { Syagrus pseudococos (Raddi) } \\
\text { Glassman } \\
\text { Asteraceae }\end{array}$ & patí & 49191 & SI & & co & $\mathrm{cs}$ & - & MA (RES/FOD) & $\mathrm{X}$ & \\
\hline Vernonia puberula Less. & cambará-guaçu & 49268 & $\mathrm{P}$ & & cs & - & - & FOD & & \\
\hline $\begin{array}{l}\text { Vernonia sp. } \\
\text { Bignoniaceae }\end{array}$ & - & 49234 & $\mathrm{NC}$ & & oc & - & - & - & & - \\
\hline $\begin{array}{l}\text { Tabebuia serratifolia (Vahl) G. } \\
\text { Nicholson } \\
\text { Boraginaceae }\end{array}$ & ipê-amarelo & 50517 & $\mathrm{C}$ & & - & co & $\mathrm{cm}$ & $\begin{array}{l}\text { AMA/CAA/CER/MA } \\
\text { (FOD/FES)/PAN }\end{array}$ & & \\
\hline Cordia cf. superba Cham. & louro-branco & 49262 & SI & & co & - & 5 & CAA/CER/MA & $\mathrm{X}$ & \\
\hline $\begin{array}{l}\text { Cordia taguahyensis Vell. } \\
\text { Burseraceae }\end{array}$ & louro-branco & 49219 & SI & & cs & $\mathrm{cs}$ & - & CAA/CER/MA & $\mathrm{X}$ & $\mathrm{X}$ \\
\hline $\begin{array}{l}\text { Protium kleinii Cuatrec. } \\
\text { Cardiopteridaceae }\end{array}$ & & 50520 & ST & VU* & - & $\mathrm{oc}$ & $\mathrm{cm}$ & MA (FOD) & $\mathrm{X}$ & \\
\hline $\begin{array}{l}\text { Citronella paniculata (Mart.) } \\
\text { R.A.Howard } \\
\text { Caricaceae }\end{array}$ & & 49148 & $\mathrm{C}$ & & co & co & $\mathrm{cm}$ & AMA/CER/MA (FOD) & & $\mathrm{X}$ \\
\hline
\end{tabular}




\begin{tabular}{|c|c|c|c|c|c|c|c|c|c|c|}
\hline Família/Espécie & Nome popular & $\mathrm{N}^{\mathbf{0}}$ IAC & 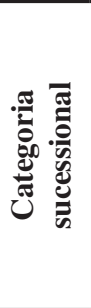 & 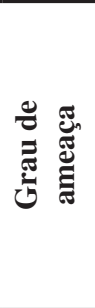 & 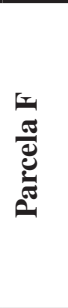 & $\frac{\pi}{d \pi}$ & 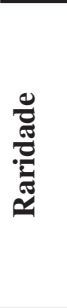 & Bioma / Fisionomia & 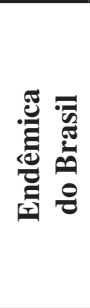 & 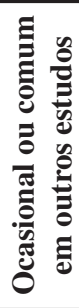 \\
\hline $\begin{array}{l}\text { Jacaratia spinosa (Aubl.) } \\
\text { A. DC. } \\
\text { Celastraceae }\end{array}$ & $\begin{array}{l}\text { mamãozinho-do- } \\
\text { mato }\end{array}$ & 49772 & NP & & - & co & $\mathrm{cm}$ & $\begin{array}{l}\text { AMA/CER/MA (FOD/ } \\
\text { FES) }\end{array}$ & & \\
\hline Maytenus robusta Reissek & & 49276 & $\mathrm{C}$ & & oc & $\mathrm{oc}$ & $\mathrm{cm}$ & $\begin{array}{l}\text { AMA/CAA/CER/MA } \\
\text { (RES/FOD/FOM/FES) }\end{array}$ & $\mathrm{X}$ & $\mathrm{X}$ \\
\hline $\begin{array}{l}\text { Maytenus ubatubensis } \\
\text { Carv.-Okano }\end{array}$ & & 50269 & $\mathrm{NC}$ & & $\mathrm{oc}$ & - & & - & & - \\
\hline Maytenus sp. & & 50268 & $\mathrm{NC}$ & & - & co & & - & & - \\
\hline $\begin{array}{l}\text { Salacia grandifolia (Mart.) } \\
\text { G. Don }\end{array}$ & & 50270 & $\mathrm{NC}$ & & - & co & & MA (FOD) & $\mathrm{X}$ & $\mathrm{X}$ \\
\hline $\begin{array}{l}\text { Tontelea aff. fluminensis (Peyr.) } \\
\text { A.C. Sm. } \\
\text { Chrysobalanaceae }\end{array}$ & & 50267 & $\mathrm{NC}$ & & - & $\mathrm{oc}$ & - & MA (FOD) & $\mathrm{X}$ & \\
\hline Couepia cf. venosa Prance & & 49174 & $\mathrm{NC}$ & & co & co & $\mathrm{cm}$ & $\mathrm{MA}(\mathrm{FOD})$ & $\mathrm{X}$ & $\mathrm{X}$ \\
\hline $\begin{array}{l}\text { Hirtella hebeclada Moric. ex } \\
\text { DC. }\end{array}$ & & 49775 & $\mathrm{C}$ & & - & oc & $\mathrm{cm}$ & $\begin{array}{c}\text { CER/MA (RES/FOD/ } \\
\text { FES) }\end{array}$ & $\mathrm{X}$ & $\mathrm{X}$ \\
\hline $\begin{array}{l}\text { Licania hoehnei Pilg. } \\
\text { Clusiaceae }\end{array}$ & & 49776 & ST & & - & co & 4 & CER/MA (FOD) & & \\
\hline $\begin{array}{l}\text { Garcinia gardneriana (Planch. } \\
\text { \& Triana) Zappi } \\
\text { Combretaceae }\end{array}$ & bacupari & 49777 & $\mathrm{C}$ & & - & cs & $\mathrm{cm}$ & $\begin{array}{c}\text { AMA/CAA/CER/MA } \\
\text { (RES/FOD/FES) }\end{array}$ & & \\
\hline Buchenavia kleinii Exell & & 49774 & ST & & - & $\mathrm{oc}$ & $\mathrm{cm}$ & MA (FOD) & $\mathrm{X}$ & $\mathrm{X}$ \\
\hline $\begin{array}{l}\text { Terminalia januariensis DC. } \\
\text { Cyatheaceae }\end{array}$ & piúna & 49178 & ST & & co & co & - & MA (FOD) & $\mathrm{X}$ & $X$ \\
\hline $\begin{array}{l}\text { Alsophila sternbergii (Sternb.) } \\
\text { D.S.Conant. }\end{array}$ & samambaiuçu & 49235 & SI & & $a b$ & co & 4 & CER/MA & $\mathrm{X}$ & \\
\hline Cyathea hirsuta C. Presl & samambaiuçu & 49292 & $\mathrm{NC}$ & & cs & - & - & MA & $\mathrm{X}$ & \\
\hline $\begin{array}{l}\text { Cyathea phalerata Mart. } \\
\text { Elaeocarpaceae }\end{array}$ & samambaiuçu & 49285 & SI & & co & co & - & CER/MA & $\mathrm{X}$ & $\mathrm{X}$ \\
\hline $\begin{array}{l}\text { Sloanea guianensis (Aubl.) } \\
\text { Benth. } \\
\text { Euphorbiaceae }\end{array}$ & sapopema & 49245 & $\mathrm{C}$ & & cs & $\mathrm{cs}$ & $\mathrm{cm}$ & AMA/CER/MA (FOD) & & \\
\hline $\begin{array}{l}\text { Alchornea glandulosa Poepp. } \\
\text { Alchornea sidifolia Müll.Arg. } \\
\text { Alchornea triplinervia } \\
\text { (Spreng.) Müll.Arg. }\end{array}$ & $\begin{array}{l}\text { boleiro; tapiá } \\
\text { tapiá } \\
\text { tapiá }\end{array}$ & $\begin{array}{l}49226 \\
49240 \\
49283\end{array}$ & $\begin{array}{l}\mathrm{P} \\
\mathrm{P} \\
\mathrm{P}\end{array}$ & & $\begin{array}{l}\text { cs } \\
\text { co } \\
\text { cs }\end{array}$ & $\begin{array}{l}\text { co } \\
- \\
\text { co }\end{array}$ & $\begin{array}{l}\mathrm{cm} \\
\mathrm{cm} \\
\mathrm{cm}\end{array}$ & $\begin{array}{c}\text { CER/MA (FOD/FES) } \\
\text { MA (FOD (SE)) } \\
\text { AMA/CAA/CER/MA } \\
\text { (FES/FOD/FOM/FED) }\end{array}$ & & $\mathrm{X}$ \\
\hline Mabea piriri Aubl. & & 49779 & $\mathrm{NC}$ & & - & co & - & AMA/CER/MA & & $\mathrm{X}$ \\
\hline $\begin{array}{l}\text { Pausandra morisiana (Casar.) } \\
\text { Radlk. }\end{array}$ & & 49780 & $\mathrm{C}$ & & - & co & $\mathrm{cm}$ & MA (RES/FOD) & $\mathrm{X}$ & \\
\hline $\begin{array}{l}\text { Sapium biglandulosum (L.) } \\
\text { Morong }\end{array}$ & & 49165 & $\mathrm{P}$ & & co & co & 5 & $\begin{array}{l}\text { AMA/CAA/CER/MA } \\
\text { (RES/FOD/FOM/FES) }\end{array}$ & & $\mathrm{X}$ \\
\hline $\begin{array}{l}\text { Tetrorchidium rubrivenium } \\
\text { Poepp } \\
\text { Fabaceae }\end{array}$ & & 49117 & $\mathrm{P}$ & & oc & - & $\mathrm{cm}$ & $\begin{array}{l}\text { AMA/CAA/MA } \\
\text { (FOD/FED) }\end{array}$ & & $X$ \\
\hline Copaifera langsdorffii Desv. & & 49783 & $\mathrm{C}$ & QA* & - & co & $\mathrm{cm}$ & $\begin{array}{l}\text { CAA/CER/MA } \\
\text { (FOD/FES) }\end{array}$ & & $X$ \\
\hline $\begin{array}{l}\text { Dahlstedtia pinnata (Benth.) } \\
\text { Malme }\end{array}$ & timbó & 49782 & SI & & - & co & 1 & MA (FOD) & $\mathrm{X}$ & $\mathrm{X}$ \\
\hline
\end{tabular}




\begin{tabular}{|c|c|c|c|c|c|c|c|c|c|c|}
\hline Família/Espécie & Nome popular & $\mathbf{N}^{\mathbf{0}}$ IAC & 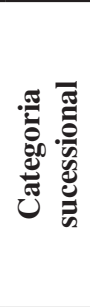 & 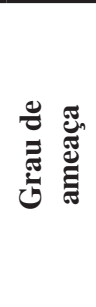 & 穿 & 吾 & 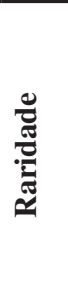 & Bioma / Fisionomia & 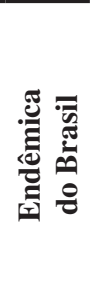 & 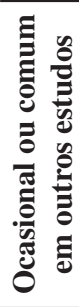 \\
\hline $\begin{array}{l}\text { Hymenaea courbaril var. } \\
\text { altissima (Ducke) Y.T. Lee \& } \\
\text { Langenh. }\end{array}$ & jatobá & 49787 & SI & & - & co & $\mathrm{cm}$ & MA & $\mathrm{X}$ & $X$ \\
\hline Inga capitata Desv. & & 49788 & SI & & - & $\mathrm{oc}$ & $\mathrm{cm}$ & AMA/MA & & $\mathrm{X}$ \\
\hline Inga edulis Mart. & ingá-macaco & 49282 & SI & & cs & oc & $\mathrm{cm}$ & $\begin{array}{c}\text { AMA/CAA/CER/MA } \\
\text { (FES/FOD/FES })\end{array}$ & & $\mathrm{X}$ \\
\hline $\begin{array}{l}\text { Inga grazielae (Vinha) } \\
\text { Pennington }\end{array}$ & & 49785 & $\mathrm{NC}$ & & - & $\mathrm{oc}$ & - & MA & $\mathrm{X}$ & \\
\hline Inga marginata Willd. & ingá-feijão & 49266 & SI & & co & - & $\mathrm{cm}$ & $\begin{array}{l}\text { AMA/CER/MA } \\
\text { (RES/FOD/FES) }\end{array}$ & & $\mathrm{X}$ \\
\hline $\begin{array}{l}\text { Lonchocarpus cultratus (Vell.) } \\
\text { A.M.G.Azevedo \& H.C.Lima }\end{array}$ & embira-de-sapo & 49243 & SI & & $\mathrm{ab}$ & co & 1 & AMA/CAA/CER/MA & & $\mathrm{X}$ \\
\hline Myrocarpus frondosus Allemão & & 49784 & NP & QA* & - & co & $\mathrm{cm}$ & MA (FOD/FES) & & $\mathrm{X}$ \\
\hline Piptadenia paniculata Benth. & vinhático & 49193 & SI & & oc & - & - & CER/MA (FOD) & $\mathrm{X}$ & \\
\hline $\begin{array}{l}\text { Pseudopiptadenia leptostachya } \\
\text { (Benth.) Rausch. }\end{array}$ & mamica-de-porca & 49186 & $\mathrm{NC}$ & & co & co & 4 & MA (FOD) & $\mathrm{X}$ & \\
\hline Pterocarpus rohrii Vahl. & sangue-de-cachorro & 49189 & ST & & $\mathrm{oc}$ & - & $\mathrm{cm}$ & $\begin{array}{l}\text { AMA/CER/MA } \\
\text { (RES/FOD/FES) }\end{array}$ & & $\mathrm{X}$ \\
\hline Swartzia langsdorffii Raddi & & 49781 & NP & QA* & - & co & - & MA (RES/FOD) & $X$ & \\
\hline Swartzia oblata R.S.Cowan & & 49169 & $\mathrm{NC}$ & & co & co & - & MA (FOD) & $X$ & \\
\hline $\begin{array}{l}\text { Tachigali denudata (Vogel) } \\
\text { Oliveira-Filho }\end{array}$ & & 49786 & $\mathrm{NC}$ & & - & co & - & MA (FOD) & $\mathrm{X}$ & \\
\hline $\begin{array}{l}\text { Zollernia ilicifolia (Brongn.) } \\
\text { Vogel } \\
\text { Lamiaceae }\end{array}$ & & 49276 & SI & & $\mathrm{oc}$ & co & $\mathrm{cm}$ & $\begin{array}{l}\text { CAA/CER/MA } \\
\text { (RES/FOD/FES) }\end{array}$ & & $\mathrm{X}$ \\
\hline $\begin{array}{l}\text { Aegiphila integrifolia (Jacq.) } \\
\text { B.D.Jacks. } \\
\text { Lauraceae }\end{array}$ & & 49303 & $\mathrm{NC}$ & & $\mathrm{oc}$ & co & & AMA/CAA/CER/MA & & \\
\hline $\begin{array}{l}\text { Cryptocarya mandioccana } \\
\text { Meisn. }\end{array}$ & canela & 49792 & NP & & - & co & & MA & $\mathrm{X}$ & \\
\hline Cryptocarya saligna Mez. & canela & 49278 & ST & & co & $\mathrm{co}$ & 4 & MA (FOD) & $\mathrm{X}$ & \\
\hline $\begin{array}{l}\text { Endlicheria paniculata } \\
\text { (Spreng.) J.F.Macbr. }\end{array}$ & canela & 49244 & $\mathrm{C}$ & & co & co & $\mathrm{cm}$ & $\begin{array}{c}\text { AMA/CER/CAA/MA } \\
(\mathrm{RES} / \mathrm{FOD} / \mathrm{FOM} / \mathrm{FES}) / \\
\text { PAN }\end{array}$ & & $\mathrm{X}$ \\
\hline $\begin{array}{l}\text { Licaria armeniaca (Ness) } \\
\text { Kosterm. }\end{array}$ & canela & 49230 & SI & & co & co & 1 & $\begin{array}{l}\text { AMA/CER/MA (FOD/ } \\
\text { FES) }\end{array}$ & & $\mathrm{X}$ \\
\hline $\begin{array}{l}\text { Nectandra membranacea (Sw.) } \\
\text { Griseb. }\end{array}$ & canela & 49246 & SI & & co & - & $\mathrm{cm}$ & $\begin{array}{l}\text { AMA/CAA/CER/MA } \\
\text { (RES(LS)/FOD) }\end{array}$ & & \\
\hline $\begin{array}{l}\text { Ocotea brachybotra (Meisn.) } \\
\text { Mez }\end{array}$ & canela-bosta & 49144 & ST & & co & - & $\mathrm{cm}$ & MA (FOD/FES) & $\mathrm{X}$ & $\mathrm{X}$ \\
\hline Ocotea dispersa (Nees) Mez & canela-sassafraz & 49149 & ST & & cs & $\mathrm{cs}$ & $\mathrm{cm}$ & MA (FOD) & $\mathrm{X}$ & $\mathrm{X}$ \\
\hline $\begin{array}{l}\text { Ocotea paranapiacabensis } \\
\text { Coe-Teixeira }\end{array}$ & canela-gosmenta & 49146 & $\mathrm{NC}$ & & $\mathrm{cs}$ & - & - & FOD & & \\
\hline $\begin{array}{l}\text { Ocotea tabacifolia (Meisn.) } \\
\text { Rohwer }\end{array}$ & & 49793 & NP & VU* & - & $\mathrm{oc}$ & 6 & AMA/MA (FOD) & $\mathrm{X}$ & \\
\hline $\begin{array}{l}\text { Ocotea teleiandra (Meisn.) } \\
\text { Mez } \\
\text { Lecythidaceae }\end{array}$ & & 49791 & $\mathrm{C}$ & & - & $\mathrm{co}$ & $\mathrm{cm}$ & MA (FOD) & $X$ & $\mathrm{X}$ \\
\hline $\begin{array}{l}\text { Cariniana estrellensis (Raddi) } \\
\text { Kuntze }\end{array}$ & jequitibá & 49140 & $\mathrm{ST}$ & QA* & co & - & $\mathrm{cm}$ & $\begin{array}{c}\text { AMA/CER/MA } \\
(\mathrm{RES}(\mathrm{LS}) / \mathrm{FOD} / \mathrm{FES})\end{array}$ & & $X$ \\
\hline
\end{tabular}




\begin{tabular}{|c|c|c|c|c|c|c|c|c|c|c|}
\hline Família/Espécie & Nome popular & $\mathrm{N}^{\circ}$ IAC & 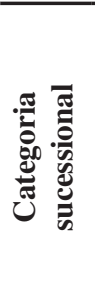 & 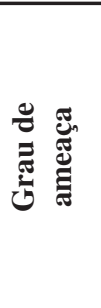 & 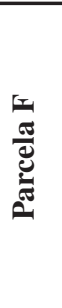 & 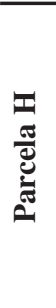 & 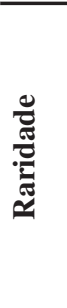 & Bioma / Fisionomia & 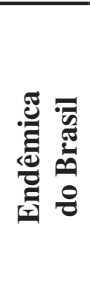 & 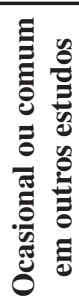 \\
\hline $\begin{array}{l}\text { Lecythis cf. lanceolata Poir } \\
\text { Magnoliaceae }\end{array}$ & & 49296 & $\mathrm{NC}$ & & - & co & - & MA & $\mathrm{X}$ & \\
\hline $\begin{array}{l}\text { Magnolia ovata (A. St.-Hil.) } \\
\text { Spreng. } \\
\text { Malvaceae }\end{array}$ & - & 50380 & $\mathrm{C}$ & & - & $\mathrm{oc}$ & $\mathrm{cm}$ & CER/MA (FOD/FES) & & $\mathrm{X}$ \\
\hline $\begin{array}{l}\text { Eriotheca pentaphylla (Vell.) } \\
\text { A. Robyns }\end{array}$ & embiruçu & 50387 & ST & & - & cs & $\mathrm{cm}$ & MA & $\mathrm{X}$ & \\
\hline $\begin{array}{l}\text { Quararibea turbinata }(\mathrm{Sw} .) \\
\text { Poir. } \\
\text { Melastomataceae }\end{array}$ & & 50385 & ST & & - & co & - & AMA/CER/MA (FOD) & & $\mathrm{X}$ \\
\hline $\begin{array}{l}\text { Henriettella glabra (Vell.) } \\
\text { Cogn. }\end{array}$ & - & 50383 & $\mathrm{P}$ & & - & oc & - & MA (FOD) & $\mathrm{X}$ & $\mathrm{X}$ \\
\hline $\begin{array}{l}\text { Leandra dasytricha (A.Gray) } \\
\text { Cogn. }\end{array}$ & & 50382 & $\mathrm{P}$ & & co & $\mathrm{oc}$ & $\mathrm{cm}$ & MA (RES/FOD/FES) & $\mathrm{X}$ & \\
\hline $\begin{array}{l}\text { Meriania caliptrata (Naudin) } \\
\text { Triana }\end{array}$ & pixirica & 49237 & $\mathrm{NC}$ & & co & oc & & MA (FOD) & $\mathrm{X}$ & \\
\hline Miconia cabucu Hoehne & pixirica & 49237 & $\mathrm{C}$ & & - & $\mathrm{oc}$ & $\mathrm{cm}$ & MA (RES/FOD) & $\mathrm{X}$ & $\mathrm{X}$ \\
\hline $\begin{array}{l}\text { Miconia cinnamomifolia (DC.) } \\
\text { Naudim }\end{array}$ & pixirica & 49267 & $\mathrm{P}$ & & oc & - & $\mathrm{cm}$ & MA (RES/FOD/FES) & $\mathrm{X}$ & \\
\hline Miconia dodecandra Cogn. & & 49301 & $\mathrm{NC}$ & & co & - & $\mathrm{cm}$ & AMA/CER/MA (FOD) & & \\
\hline Miconia cf. picinguabensis & & 50386 & $\mathrm{NC}$ & & - & co & - & $\mathrm{MA}(\mathrm{FOD})$ & $\mathrm{X}$ & $\mathrm{X}$ \\
\hline $\begin{array}{l}\text { Miconia tristis subsp. australis } \\
\text { Wurdack }\end{array}$ & & 50452 & SI & & oc & co & 7 & MA (FOD) & & \\
\hline Miconia sp.1 & pixirica & 49263 & $\mathrm{NC}$ & & co & co & & - & & - \\
\hline $\begin{array}{l}\text { Mouriri chamissoana Cogn. } \\
\text { Meliaceae }\end{array}$ & & 50381 & $\mathrm{C}$ & & - & co & $\mathrm{cm}$ & MA (FOD) & $\mathrm{X}$ & $\mathrm{X}$ \\
\hline $\begin{array}{l}\text { Cabralea canjerana (Vell.) } \\
\text { Mart. subsp. canjerana }\end{array}$ & canjarana & 49222 & $\mathrm{C}$ & & cs & oc & $\mathrm{cm}$ & $\begin{array}{c}\text { AMA/CER/MA } \\
\text { (RES/FOD/FOM/FES) }\end{array}$ & $\mathrm{X}$ & \\
\hline $\begin{array}{l}\text { Guarea macrophylla Vahl. } \\
\text { subsp. tuberculata } \\
\text { Monimiaceae }\end{array}$ & & 49269 & $\mathrm{C}$ & QA* & co & co & $\mathrm{cm}$ & $\begin{array}{l}\text { AMA/CER/MA } \\
\text { (RES/FOD/FES) }\end{array}$ & & $\mathrm{X}$ \\
\hline Mollinedia boracensis Peixoto & & 49797 & $\mathrm{NC}$ & VU** & - & co & & MA (FOD) & $\mathrm{X}$ & $\mathrm{X}$ \\
\hline $\begin{array}{l}\text { Mollinedia lamprophylla } \\
\text { Perkins }\end{array}$ & & 49794 & $\mathrm{NC}$ & $\mathrm{VU} * *$ & - & co & & MA & $\mathrm{X}$ & $\mathrm{X}$ \\
\hline Mollinedia oligantha Perkins & & 49796 & $\mathrm{NC}$ & & - & cs & 4 & MA (FOD) & $\mathrm{X}$ & \\
\hline $\begin{array}{l}\text { Mollinedia schottiana (Spreng.) } \\
\text { Perkins }\end{array}$ & & 49158 & ST & & cs & cs & $\mathrm{cm}$ & MA (FOD/FES) & $\mathrm{X}$ & \\
\hline $\begin{array}{l}\text { Mollinedia uleana Perkins } \\
\text { Moraceae }\end{array}$ & & 49795 & ST & & - & oc & $\mathrm{cm}$ & MA (FOD/FES) & $\mathrm{X}$ & $\mathrm{X}$ \\
\hline $\begin{array}{l}\text { Brosimum lactescens } \\
\text { (S. Moore) C.C. Berg }\end{array}$ & & 49800 & $\mathrm{C}$ & & - & oc & $\mathrm{cm}$ & AMA/CER/CAA/MA & & \\
\hline Ficus insipida Willd. & figueira-mata-pau & 49156 & ST & & co & - & $\mathrm{cm}$ & $\begin{array}{l}\text { AMA/CER/MA } \\
\text { (RES/FOD/FES) }\end{array}$ & & $\mathrm{X}$ \\
\hline Ficus obtusiuscula (Miq.) Miq. & figueira & 49109 & $\mathrm{NC}$ & & oc & - & - & $\begin{array}{l}\text { AMA/CAA/CER/MA } \\
\text { (FOD) }\end{array}$ & & \\
\hline $\begin{array}{l}\text { Ficus pulchella Schott ex } \\
\text { Spreng. }\end{array}$ & ipiúna & 49300 & $\mathrm{NC}$ & & oc & - & - & $\begin{array}{l}\text { AMA/CAA/CER/MA } \\
\text { (FOD) }\end{array}$ & & $\mathrm{X}$ \\
\hline $\begin{array}{l}\text { Sorocea hilarii Gaudich. } \\
\text { Myristicaceae }\end{array}$ & & 49801 & SI & & - & co & - & CER/MA & $\mathrm{X}$ & $\mathrm{X}$ \\
\hline
\end{tabular}




\begin{tabular}{|c|c|c|c|c|c|c|c|c|c|c|}
\hline Família/Espécie & Nome popular & $\mathbf{N}^{0}$ IAC & 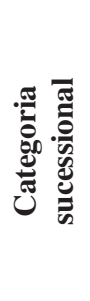 & 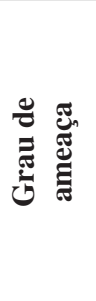 & 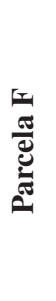 & 晃 & : & Bioma / Fisionomia & 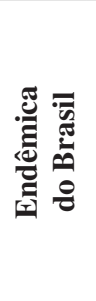 & 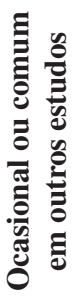 \\
\hline $\begin{array}{l}\text { Virola bicuhyba (Schott ex } \\
\text { Spreng.) Warb. } \\
\text { Myrsinaceae }\end{array}$ & bicuíba & 49115 & $\mathrm{C}$ & & co & co & $\mathrm{cm}$ & AMA (RES/FOD) & $\mathrm{X}$ & \\
\hline Ardisia martiana Miq. & manduberana & 49152 & NP & & co & cs & - & MA (FOD) & $\mathrm{X}$ & $\mathrm{X}$ \\
\hline $\begin{array}{l}\text { Rapanea ferruginea (Ruiz \& } \\
\text { Pav.) Mez }\end{array}$ & capororoca & 49170 & $\mathrm{P}$ & & $\mathrm{oc}$ & - & $\mathrm{cm}$ & $\begin{array}{c}\text { CER/MA } \\
(\text { FOD/FOM/FES) }\end{array}$ & & $\mathrm{X}$ \\
\hline $\begin{array}{l}\text { Rapanea hermogenesii Jung- } \\
\text { Mend. \& Bernacci } \\
\text { Myrtaceae }\end{array}$ & & 49852 & ST & & - & cs & 4 & MA (FOD) & $\mathrm{X}$ & $\mathrm{X}$ \\
\hline $\begin{array}{l}\text { Calyptranthes grandifolia } \\
\text { O.Berg }\end{array}$ & araçarana & 49238 & $\begin{array}{l}\mathrm{C} \\
\mathrm{ST}\end{array}$ & & co & cs & $\mathrm{cm}$ & MA (FOD) & & \\
\hline $\begin{array}{l}\text { Calyptranthes lanceolata } \mathrm{O} \text {. } \\
\text { Berg }\end{array}$ & & 49861 & $\mathrm{NC}$ & & - & oc & 4 & MA & $\mathrm{X}$ & \\
\hline $\begin{array}{l}\text { Calyptranthes lucida Mart. ex } \\
\text { DC. }\end{array}$ & araçarana & 49145 & ST & & co & cs & $\mathrm{cm}$ & AMA/MA (FOD) & & $X$ \\
\hline Calyptranthes strigipes $\mathrm{O}$. Berg & & 49877 & ST & & - & co & $\mathrm{cm}$ & $\mathrm{MA}(\mathrm{FOD})$ & $X$ & \\
\hline $\begin{array}{l}\text { Campomanesia guaviroba } \\
\text { (DC.) Kiaersk. }\end{array}$ & & 49136 & SI & & cs & - & $\mathrm{cm}$ & CER/MA & & $\mathrm{X}$ \\
\hline $\begin{array}{l}\text { Campomanesia laurifolia } \\
\text { Gardner }\end{array}$ & & 49875 & $\mathrm{NC}$ & & - & co & - & MA & $X$ & \\
\hline Eugenia batingabranca Sobral & araçarana & 49112 & $\mathrm{NC}$ & & - & oc & - & MA & $\mathrm{X}$ & \\
\hline Eugenia cf. bocainensis Mattos & & 49871 & $\mathrm{NC}$ & & - & co & - & MA & $\mathrm{X}$ & \\
\hline Eugenia cerasiflora Miq. & & 49865 & ST & & - & co & $\mathrm{cm}$ & CAA/CER/MA (FOD) & & $X$ \\
\hline $\begin{array}{l}\text { Eugenia cuprea (O. Berg) } \\
\text { Mattos }\end{array}$ & & 49867 & $\mathrm{NC}$ & & - & oc & 4 & MA & $\mathrm{X}$ & $X$ \\
\hline Eugenia excelsa $\mathrm{O}$. Berg & & 49869 & ST & & - & co & $\mathrm{cm}$ & AMA/MA & & $\mathrm{X}$ \\
\hline Eugenia involucrata DC. & & 49858 & NP & & - & $\mathrm{oc}$ & $\mathrm{cm}$ & $\begin{array}{c}\text { CER/MA } \\
\text { (FOD/FOM/FES) }\end{array}$ & & \\
\hline Eugenia monosperma Vell. & araçarana & 49151 & $\mathrm{NC}$ & & co & $\mathrm{co}$ & $\mathrm{cm}$ & MA & $X$ & $X$ \\
\hline $\begin{array}{l}\text { Eugenia mosenii (Kasusel) } \\
\text { Sobral }\end{array}$ & araçarana & 49853 & ST & & - & co & 4 & MA & $\mathrm{X}$ & \\
\hline $\begin{array}{l}\text { Eugenia multicostata D. } \\
\text { Legrand }\end{array}$ & & 49855 & NP & & - & co & $\mathrm{cm}$ & MA (FOD) & $\mathrm{X}$ & $X$ \\
\hline Eugenia neoaustralis Sobral & & 49873 & $\mathrm{NC}$ & & co & co & - & MA (FOD) & $\mathrm{X}$ & $X$ \\
\hline Eugenia oblongata O.Berg & araçarana & 49236 & ST & & co & cs & $\mathrm{cm}$ & MA (FOD) & $\mathrm{X}$ & \\
\hline Eugenia prasina O.Berg & araçarana & 49171 & ST & $\mathrm{VU}^{*}$ & co & cs & 4 & MA (FOD) & $\mathrm{X}$ & \\
\hline Eugenia subavenia $\mathrm{O}$. Berg & araçarana & 49874 & ST & & - & co & $\mathrm{cm}$ & MA (FOD) & $\mathrm{X}$ & $X$ \\
\hline $\begin{array}{l}\text { Eugenia cf. supraaxillaris } \\
\text { Spring }\end{array}$ & araçarana & 49142 & $\mathrm{NC}$ & & oc & co & - & & & \\
\hline Eugenia tinguyensis Cambess. & araçarana & 49242 & ST & & co & - & - & MA (FOD) & $\mathrm{X}$ & \\
\hline Eugenia sp. & araçarana & 49272 & $\mathrm{NC}$ & & cs & - & - & - & & - \\
\hline $\begin{array}{l}\text { Marlierea glazioviana } \\
\text { Kiareskou }\end{array}$ & araçarana & 49274 & $\mathrm{NC}$ & & $\mathrm{oc}$ & co & & MA (FOD) & $\mathrm{X}$ & $\mathrm{X}$ \\
\hline Marlierea racemosa $\mathrm{L}$. & & 49884 & $\mathrm{NC}$ & & - & co & $\mathrm{cm}$ & MA & $\mathrm{X}$ & \\
\hline Marlierea suaveolens Cambess. & & 49885 & $\mathrm{NC}$ & & - & $\mathrm{oc}$ & 5 & MA & $\mathrm{X}$ & $X$ \\
\hline $\begin{array}{l}\text { Marlierea sylvatica (O.Berg) } \\
\text { Kiaersk. }\end{array}$ & araçarana & 49175 & $\mathrm{NC}$ & & co & co & $\mathrm{cm}$ & MA (FOD) & $\mathrm{X}$ & $\mathrm{X}$ \\
\hline Marlierea tomentosa Cambess. & araçarana & 49150 & ST & & co & $\mathrm{cs}$ & $\mathrm{cm}$ & CER/MA (FOD) & $\mathrm{X}$ & \\
\hline
\end{tabular}




\begin{tabular}{|c|c|c|c|c|c|c|c|c|c|c|}
\hline Família/Espécie & Nome popular & $\mathbf{N}^{0}$ IAC & 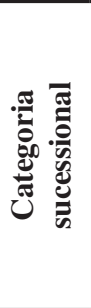 & שี & 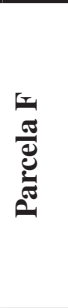 & تِ & 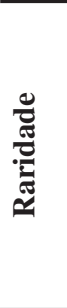 & Bioma / Fisionomia & 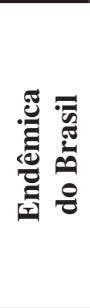 & 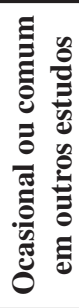 \\
\hline $\begin{array}{l}\text { Myrceugenia myrcioides } \\
\text { (Cambess.) O.Berg }\end{array}$ & araçarana & 49260 & $\mathrm{NC}$ & & cs & co & $\mathrm{cm}$ & MA (FOD) & $\mathrm{X}$ & $\mathrm{X}$ \\
\hline Myrcia pubipetala Miq. & & 49879 & $\mathrm{C}$ & & - & co & & MA (FOD) & $X$ & $\mathrm{X}$ \\
\hline $\begin{array}{l}\text { Myrcia richardiana (O. Berg) } \\
\text { Kiaersk. }\end{array}$ & & 49880 & ST & & - & co & & MA (FOD) & $\mathrm{X}$ & $\mathrm{X}$ \\
\hline Myrcia spectabilis DC. & arco-de-peneira & 49135 & $\begin{array}{l}\text { C; } \\
\text { ST }\end{array}$ & & cs & - & & MA & $\mathrm{X}$ & \\
\hline Myrcia sp. & araçarana & 49187 & $\mathrm{NC}$ & & - & & - & - & & - \\
\hline Myrcia sp.2 & & 49860 & $\mathrm{NC}$ & & co & & - & - & & - \\
\hline Myrcia sp.3 & & 49878 & $\mathrm{NC}$ & & - & cs & - & - & & - \\
\hline $\begin{array}{l}\text { Myrciaria floribunda (H.West } \\
\text { ex Willd.) O.Berg }\end{array}$ & & 49239 & ST & & co & cs & $\mathrm{cm}$ & $\begin{array}{l}\text { AMA/CAA/CER/MA } \\
\text { (FOD) }\end{array}$ & & $X$ \\
\hline $\begin{array}{l}\text { Neomitranthes glomerata (D. } \\
\text { Legrand) D. Legrand } \\
\text { Nyctaginaceae }\end{array}$ & & 50515 & ST & & - & co & $\mathrm{cm}$ & MA (FOD) & $\mathrm{X}$ & $X$ \\
\hline $\begin{array}{l}\text { Guapira hirsuta (Choisy) } \\
\text { Lundell }\end{array}$ & & 49894 & $\mathrm{NC}$ & & - & co & - & AMA/CAA/CER/MA & & \\
\hline Guapira opposita(Vell.) Reitz & louro-branco & 49172 & SI & & cs & cs & $\mathrm{cm}$ & $\begin{array}{l}\text { AMA/CAA/CER/MA } \\
\text { (RES/FOD/FES/FED) }\end{array}$ & & \\
\hline Ochnaceae & & & & & & & & & & \\
\hline $\begin{array}{l}\text { Ouratea parvifolia Engl. } \\
\text { Olacaceae }\end{array}$ & & 49850 & ST & & - & $\mathrm{cs}$ & 5 & CAA/CER & $\mathrm{X}$ & $X$ \\
\hline Heisteria silvianii Schwacke & & 49897 & $\mathrm{C}$ & & - & co & $\mathrm{cm}$ & CER/MA & $\mathrm{X}$ & \\
\hline $\begin{array}{l}\text { Tetrastylidium grandifolium } \\
\text { (Baill.) Sleumer } \\
\text { Phyllantaceae }\end{array}$ & & 49898 & $\mathrm{NC}$ & & - & co & $\mathrm{cm}$ & MA (FOD) & $\mathrm{X}$ & \\
\hline $\begin{array}{l}\text { Hyeronima alchorneoides } \\
\text { Allemão } \\
\text { Phytollacaceae }\end{array}$ & iricurana & 49217 & $\mathrm{C}$ & & cs & co & $\mathrm{cm}$ & $\begin{array}{l}\text { AMA/CAA/CER/MA } \\
\text { (RES/FOD/FES)/PAM }\end{array}$ & & \\
\hline $\begin{array}{l}\text { Phytolacca dioica } \mathrm{L} . \\
\text { Piperaceae }\end{array}$ & cebolão; maria-mole & 49287 & $\mathrm{P}$ & & cs & - & $\mathrm{cm}$ & MA (FOD/FES) & & \\
\hline Piper cernuum Vell. & & 49294 & $\mathrm{NC}$ & & $\mathrm{co}$ & - & $\mathrm{cm}$ & AMA/CER/MA (FOD) & & \\
\hline Piper gaudichaudianum Kunth & & 49233 & $\mathrm{CS}$ & & co & - & $\mathrm{cm}$ & MA (FOD) & $X$ & \\
\hline $\begin{array}{l}\text { Piper rivinoides Kunth } \\
\text { Polygonaceae }\end{array}$ & & 49299 & SI & & oc & - & - & MA (FOD) & $\mathrm{X}$ & \\
\hline $\begin{array}{l}\text { Coccoloba glaziovii Lind. } \\
\text { Quiinaceae }\end{array}$ & & 49297 & $\mathrm{NC}$ & & oc & - & - & MA(FOD/FES) & $\mathrm{X}$ & \\
\hline $\begin{array}{l}\text { Quiina glaziovii Engl. } \\
\text { Rubiaceae }\end{array}$ & & 49139 & ST & & oc & - & $\mathrm{cm}$ & MA (FOD) & & $\mathrm{X}$ \\
\hline Alseis floribunda Schott & arariba & 49181 & SI & & co & co & $\mathrm{cm}$ & $\begin{array}{l}\text { AMA/CAA/MA } \\
\text { (RES/FOD/FES) }\end{array}$ & $\mathrm{X}$ & $\mathrm{X}$ \\
\hline $\begin{array}{l}\text { Bathysa australis (A.St.-Hil.) } \\
\text { Benth. \& Hook. }\end{array}$ & corujeiro & 49249 & SI & & $\mathrm{ab}$ & cs & & MA (FOD) (?) & $X$ & $\mathrm{X}$ \\
\hline Bathysa mendoncaei K. Schum. & & 49921 & ST & & - & cs & - & MA (FOD) & $\mathrm{X}$ & \\
\hline $\begin{array}{l}\text { Bathysa stipulata (Vell.) } \\
\text { C.Presl. }\end{array}$ & & 49919 & $\mathrm{NC}$ & & - & co & - & MA (FOD) & $\mathrm{X}$ & \\
\hline $\begin{array}{l}\text { cf. Chomelia pohliana Müll. } \\
\text { Arg. }\end{array}$ & & 49899 & $\mathrm{NC}$ & & - & oc & - & - & & - \\
\hline Coussarea accedens Müll.Arg. & & 49252 & ST & & $\mathrm{co}$ & $\mathrm{cs}$ & - & MA (FOD) & $\mathrm{X}$ & \\
\hline
\end{tabular}


Tabela 1. Continuação...

\begin{tabular}{|c|c|c|c|c|c|c|c|c|c|c|}
\hline Família/Espécie & Nome popular & $\mathbf{N}^{0}$ IAC & 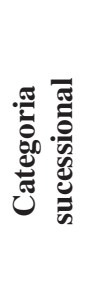 & 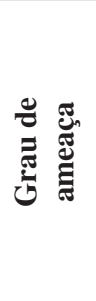 & 止 & 要 & 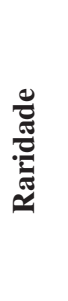 & Bioma / Fisionomia & 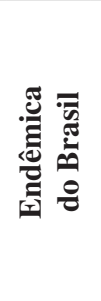 & 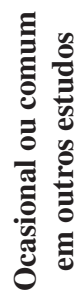 \\
\hline $\begin{array}{l}\text { Coussarea meridionalis var. } \\
\text { porophylla (Vell.) M.Gomes }\end{array}$ & & 49154 & ST & & co & cs & - & MA (FOD) & $\mathrm{X}$ & \\
\hline $\begin{array}{l}\text { Coutarea hexandra (Jacq.) K. } \\
\text { Schum. }\end{array}$ & & 49908 & ST & & - & oc & $\mathrm{cm}$ & $\begin{array}{l}\text { AMA/CAA/CER/ } \\
\text { MA(FOD/FES) }\end{array}$ & & \\
\hline $\begin{array}{l}\text { Faramea pachyantha Müll. } \\
\text { Arg. }\end{array}$ & & 50519 & $\mathrm{NC}$ & & - & co & - & MA (FOD) & $\mathrm{X}$ & $\mathrm{X}$ \\
\hline $\begin{array}{l}\text { Posoqueria latifolia (Rudge) } \\
\text { Roem. \& Schult. }\end{array}$ & & 49907 & SI & & - & co & $\mathrm{cm}$ & $\begin{array}{l}\text { AMA/CER/MA } \\
\text { (RES/FOD/FES) }\end{array}$ & & $\mathrm{X}$ \\
\hline $\begin{array}{l}\text { Psychotria birotula L.B.Sm. \& } \\
\text { Downs }\end{array}$ & & 49298 & $\mathrm{NC}$ & & co & co & - & FOD & & \\
\hline $\begin{array}{l}\text { Psychotria nuda (Cham. \& } \\
\text { Schltdl.) Wawra }\end{array}$ & & 49179 & $\mathrm{C}$ & & $\mathrm{cs}$ & cs & $\mathrm{cm}$ & MA (FOD) & $\mathrm{X}$ & $\mathrm{X}$ \\
\hline Randia sp.1 & & 49900 & $\mathrm{NC}$ & & - & co & - & - & & - \\
\hline Randia sp.2 & & 49901 & $\mathrm{NC}$ & & - & oc & - & - & & - \\
\hline $\begin{array}{l}\text { Rudgea jasminoides (Cham.) } \\
\text { Müll.-Arg. }\end{array}$ & & 49279 & $\mathrm{C}$ & & co & $a b$ & $\mathrm{~cm}$ & MA (FOD) & & $\mathrm{X}$ \\
\hline Rudgea velerea Müll. Arg. & & 49910 & ST & & - & cs & - & MA (RES/FOD) & $\mathrm{X}$ & $X$ \\
\hline $\begin{array}{l}\text { Rustia formosa (Cham. \& } \\
\text { Schltdl. ex DC.) Klotzsch } \\
\text { Rutaceae }\end{array}$ & & 49906 & $\mathrm{P}$ & & - & oc & 5 & CER/MA (FOD) & $\mathrm{X}$ & \\
\hline Zanthoxylum fagara (L.) Sarg. & mamica-de-porca & 49228 & NP & & co & - & $\mathrm{cm}$ & $\begin{array}{l}\text { AMA/CER/MA } \\
\text { (FOD/FES/FED) }\end{array}$ & & $\mathrm{X}$ \\
\hline \multicolumn{11}{|l|}{ Salicaceae } \\
\hline Casearia sylvestris $\mathrm{Sw}$. & & 49288 & $\mathrm{P}$ & & $\mathrm{oc}$ & $\mathrm{oc}$ & $\mathrm{cm}$ & $\begin{array}{c}\text { AMA/CAA/CER/ } \\
\text { MA(RES/FOD/FES)/ } \\
\text { PAM/PAN }\end{array}$ & & $\mathrm{X}$ \\
\hline \multicolumn{11}{|l|}{ Sapindaceae } \\
\hline Allophylus petiolulatus Radlk. & & 49143 & $\mathrm{NC}$ & & $\mathrm{oc}$ & co & 1 & MA (RES/FOD/FES) & & $\mathrm{X}$ \\
\hline Cupania furfuracea Radlk. & & 50205 & $\mathrm{NC}$ & & - & co & - & CER/MA (FOD) & & \\
\hline Cupania oblongifolia Mart. & cubatão & 49220 & SI & & co & co & $\mathrm{cm}$ & $\begin{array}{l}\text { AMA/CER/MA } \\
\text { (RES/FOD) }\end{array}$ & & \\
\hline $\begin{array}{l}\text { Matayba intermedia Radlk. } \\
\text { Sapotaceae }\end{array}$ & & 50207 & $\mathrm{NC}$ & & - & oc & & MA (FOD) & $\mathrm{X}$ & \\
\hline Chrysophyllum flexuosum Mart. & & 49930 & ST & & - & cs & - & MA & $\mathrm{X}$ & \\
\hline Ecclinusa ramiflora Mart. & guacá & 49928 & ST & & - & co & $\mathrm{cm}$ & AMA/MA & & $\mathrm{X}$ \\
\hline $\begin{array}{l}\text { Micropholis crassipedicellata } \\
\text { (Mart. \& Eichler ex Miq.) } \\
\text { Pierre }\end{array}$ & & 49925 & ST & & - & co & $\mathrm{cm}$ & MA & $\mathrm{X}$ & $\mathrm{X}$ \\
\hline $\begin{array}{l}\text { Pouteria caimito (Ruiz \& Pav.) } \\
\text { Radlk. }\end{array}$ & & 49927 & ST & & - & co & $\mathrm{cm}$ & $\begin{array}{l}\text { AMA/CER/MA } \\
\text { (RES/FOD) }\end{array}$ & & $\mathrm{X}$ \\
\hline $\begin{array}{l}\text { Pouteria aff. torta (Mart.) } \\
\text { Radlk. }\end{array}$ & & 50551 & SI & & - & oc & - & FOD/FES/CER & & \\
\hline $\begin{array}{l}\text { Pouteria psammophila (Mart.) } \\
\text { Radlk. }\end{array}$ & & 49290 & $\mathrm{NC}$ & & $\mathrm{cs}$ & cs & $\mathrm{cm}$ & MA (RES/FOD) & $X$ & $\mathrm{X}$ \\
\hline Pouteria sp.1 & & 49926 & $\mathrm{NC}$ & & - & oc & - & - & & - \\
\hline $\begin{array}{l}\text { Pouteria sp. } 2 \\
\text { Siparunaceae }\end{array}$ & & 50511 & $\mathrm{NC}$ & & - & co & - & - & & - \\
\hline $\begin{array}{l}\text { Siparuna brasiliensis (Spreng.) } \\
\text { A.DC. }\end{array}$ & $\begin{array}{l}\text { erva-de-limão; } \\
\text { limão-bravo }\end{array}$ & 49184 & NP & VU* & cs & - & - & CER/MA (FOD)/PAN & & \\
\hline
\end{tabular}


Tabela 1. Continuação...

\begin{tabular}{|c|c|c|c|c|c|c|c|c|c|c|}
\hline Família/Espécie & Nome popular & $\mathbf{N}^{\circ}$ IAC & 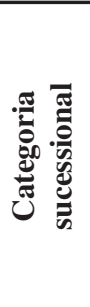 & 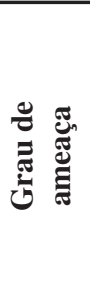 & ت & 要 & 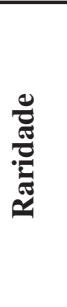 & Bioma / Fisionomia & 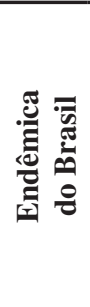 & 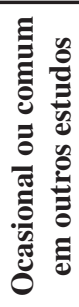 \\
\hline \multicolumn{11}{|l|}{ Solanaceae } \\
\hline Solanum cf. bullatum Vell. & & 49185 & $\mathrm{P}$ & & co & - & 4 & MA (FOD/FOM) & $X$ & \\
\hline $\begin{array}{l}\text { Solanum swartzianum Roem. } \\
\& \text { Schult. }\end{array}$ & & 49116 & PI & & co & - & 4 & CER/MA (FOD) & $\mathrm{X}$ & $X$ \\
\hline $\begin{array}{l}\text { Solanum sp. } \\
\text { Symplocaceae }\end{array}$ & & 49138 & $\mathrm{NC}$ & & co & - & - & - & & - \\
\hline $\begin{array}{l}\text { Symplocos variabilis Mart. } \\
\text { Thymeleaceae }\end{array}$ & & 50518 & $\mathrm{NC}$ & & - & $\mathrm{co}$ & 4 & MA (FOD) & $\mathrm{X}$ & \\
\hline $\begin{array}{l}\text { Daphnopsis schwackeana } \\
\text { Taub. } \\
\text { Urticaceae }\end{array}$ & & 50209 & NP & & - & $\mathrm{co}$ & 4 & MA (FOD) & $\mathrm{X}$ & \\
\hline Cecropia glaziovii Snethl. & embaúba & 49270 & $\mathrm{P}$ & & cs & co & $\mathrm{cm}$ & MA (RES/FOD/FES) & $X$ & \\
\hline Cecropia pachystachya Trécul. & embaúba & 49254 & $P$ & & oc & - & $\mathrm{cm}$ & $\begin{array}{l}\text { AMA/CAA/CER/MA } \\
\text { (RES/FOD/FES)/PAN }\end{array}$ & & \\
\hline $\begin{array}{l}\text { Coussapoa microcarpa (Schott) } \\
\text { Rizzini }\end{array}$ & figueira & 49137 & ST & & oc & co & $\mathrm{cm}$ & $\begin{array}{c}\text { CER/MA(RES/FOD/ } \\
\text { FES })\end{array}$ & $X$ & $X$ \\
\hline Pourouma guianensis Aubl. & embaubú & 49110 & SI & & co & $\mathrm{oc}$ & $\mathrm{cm}$ & AMA/MA (RES/FOD) & & \\
\hline $\begin{array}{l}\text { Urera baccifera (L.) Gaudich. } \\
\text { ex Wedd. } \\
\text { Verbenaceae }\end{array}$ & urtiga & 49157 & ST & & oc & $\mathrm{co}$ & $\mathrm{cm}$ & $\begin{array}{l}\text { AMA/CER/MAR } \\
\text { (FOD/FES) }\end{array}$ & & \\
\hline $\begin{array}{l}\text { Citharexylum myrianthum } \\
\text { Cham. } \\
\text { Indeterminadas }\end{array}$ & tarumã & 49225 & $\mathrm{P}$ & & oc & - & $\mathrm{cm}$ & $\begin{array}{c}\text { CAA/CER/MA }(\text { RES/ } \\
\text { FOD/FES })\end{array}$ & & \\
\hline Indeterminada sp. 1 & & 49302 & $\mathrm{NC}$ & & - & - & - & - & & - \\
\hline Indeterminada sp. 2 & & 50514 & $\mathrm{NC}$ & & - & $\mathrm{oc}$ & - & - & & - \\
\hline Indeterminada sp.3 & & 50513 & $\mathrm{NC}$ & & - & $\mathrm{oc}$ & - & - & & - \\
\hline Indeterminada sp.4 & & 50512 & $\mathrm{NC}$ & & - & oc & - & - & & - \\
\hline
\end{tabular}

parcela $\mathrm{H}$ estas espécies também ocorrem, mas com número bem menor de indivíduos.

Houve diferença significativa $(\mathrm{t}=-4,0464 ; \mathrm{p}<0.05)$ entre os valores de áreas basal entre os dois trechos, que na parcela $\mathrm{F}$ foi de $31,26 \mathrm{~m}^{2}$, onde as árvores mortas ocupam a sexta posição em ordem de importância com área basal de 2,38 m². Na parcela $\mathrm{H}$ o valor da área basal total foi de $37,78 \mathrm{~m}^{2}$, as árvores mortas ocupam a terceira posição e a área basal é $3,16 \mathrm{~m}^{2}$. Na parcela $\mathrm{F}$ foi relatado e também observado que a madeira oriunda de árvores caídas ou quebradas é frequentemente retirada para uso como lenha, e talvez esta atividade tenha influenciado no número de árvores mortas em pé, que é menor nesta área em relação à parcela $\mathrm{H}$.

Foi observada a ocorrência de dois estratos arbóreos e árvores emergentes. $\mathrm{O}$ estrato inferior situa-se entre 1,3 e $11 \mathrm{~m}$, e engloba a maioria dos indivíduos amostrados. $\mathrm{O}$ estrato superior é formado por árvores de 11 a $18 \mathrm{~m}$ e os poucos indivíduos emergentes atingem $25 \mathrm{~m}$ de altura. A diferença entre os trechos se deve aos indivíduos de menor porte, mais numerosos no trecho mais alto (Figura 2).

Nos dois trechos a grande maioria dos indivíduos apresenta diâmetros menores (Figura 3). A abundância das árvores é inversamente proporcional às suas medidas de circunferência, ou seja, árvores de menor diâmetro são mais abundantes e quanto maior o diâmetro, menor a quantidade de indivíduos. Rangel et al. (2006) atribuíram esta característica a comunidades que se auto-regeneram, cujas espécies apresentam recrutamento contínuo. Entre as árvores de maior diâmetro ocorrentes na parcela F estão Alchornea triplinervea, Phytollaca dioica, Hyeronima alcorneoides, Pouteria psammophila, Inga edulis, Sloanea guianensis e Cabralea canjerana e as espécies que se destacam pela grande área basal são Bathysa australis, Hyeronima alchorneoides, Alsophila sternbergii e Lonchocarpus cultratus, todas bastante abundantes. Na parcela $\mathrm{H}$ as árvores de maior diâmetro pertencem às espécies Pouteria psammophila, Alchornea triplinervea, Eriotheca pentaphylla e Swartzia langsdorffii, e as espécies de grande área basal são Eriotheca pentaphylla, Guapira opposita, Sloanea guianensis e Pouteria psammophila. Apesar de serem mais abundantes, $R$. jasminoides e $E$. edulis não estão entre as primeiras colocadas (Tabela 2).

Na parcela $\mathrm{F}$ os poucos indivíduos remanescentes de Euterpe edulis ocorrem em locais mais distantes da trilha, sendo que os maiores, com 10 e $11 \mathrm{~m}$ de altura, encontram-se nos locais menos acessíveis da parcela, onde a topografia do terreno, rochas e muitas trepadeiras dificultam a passagem. Além das evidências de corte, 
Tabela 2. Espécies amostradas aos $100 \mathrm{~m}$ de altitude na Fazenda Capricórnio, Ubatuba, PESM (SP) e seus respectivos parâmetros fitossociológicos, em ordem decrescente de IVI. NI= número de indivíduos; $\mathrm{DR}=$ dominância relativa; FA = freqüência absoluta; FR freqüência relativa; DoA = dominância absoluta; DoR dominância relativa; IVC = índice de valor e cobertura; IVI = índice de valor de importância.

Table 2. Sampled species at $100 \mathrm{~m}$ altitude in Capricórnio Farm, Ubatuba, PESM (SP) and their quantitative parameters ordered in decreasingly values of VI. $\mathrm{NI}=$ individual numbers; $\mathrm{DR}=$ relative dominance; $\mathrm{FA}=$ absolute frequency $; \mathrm{FR}=$ relative frequence; DoA = absolute dominance; DoR = relative dominance; $\mathrm{IVC}=$ coverage value index; IVI $=$ importance value index.

\begin{tabular}{|c|c|c|c|c|c|c|c|c|}
\hline Espécies & NInd & RelDe & AbsFr & RelFr & AbsDo & RelDo & IVI & IVC \\
\hline Bathysa australis & 229 & 16,3 & 84 & 9,28 & 4,18 & 13,28 & 38,86 & 29,57 \\
\hline Lonchocarpus cultratus & 145 & 10,32 & 56 & 6,19 & 1,95 & 6,19 & 22,7 & 16,51 \\
\hline Alsophila sternbergii & 103 & 7,33 & 44 & 4,86 & 2,28 & 7,23 & 19,43 & 14,57 \\
\hline Hyeronima alchorneoides & 63 & 4,48 & 41 & 4,53 & 2,88 & 9,15 & 18,16 & 13,63 \\
\hline Guapira opposita & 80 & 5,69 & 51 & 5,64 & 0,75 & 2,38 & 13,71 & 8,08 \\
\hline mortas & 26 & 1,85 & 22 & 2,43 & 2,38 & 7,54 & 11,83 & 9,4 \\
\hline Alchornea triplinervia & 38 & 2,7 & 28 & 3,09 & 1,08 & 3,41 & 9,21 & 6,12 \\
\hline Mollinedia schottiana & 51 & 3,63 & 34 & 3,76 & 0,28 & 0,88 & 8,27 & 4,51 \\
\hline Rollinia dolabripetala & 35 & 2,49 & 25 & 2,76 & 0,74 & 2,34 & 7,6 & 4,84 \\
\hline Eugenia sp.1 & 40 & 2,85 & 34 & 3,76 & 0,19 & 0,59 & 7,2 & 3,44 \\
\hline Phytolacca dioica & 15 & 1,07 & 12 & 1,33 & 1,5 & 4,76 & 7,15 & 5,83 \\
\hline Pouteria psammophila & 16 & 1,14 & 15 & 1,66 & 1,32 & 4,19 & 6,99 & 5,33 \\
\hline Cecropia glaziovii & 39 & 2,78 & 17 & 1,88 & 0,7 & 2,23 & 6,89 & 5,01 \\
\hline Myrceugenia myrcioides & 38 & 2,7 & 29 & 3,2 & 0,3 & 0,94 & 6,85 & 3,65 \\
\hline Alchornea glandulosa & 34 & 2,42 & 19 & 2,1 & 0,66 & 2,09 & 6,61 & 4,51 \\
\hline Inga edulis & 11 & 0,78 & 9 & 0,99 & 1,29 & 4,11 & 5,89 & 4,89 \\
\hline Cordia taguahyensis & 27 & 1,92 & 23 & 2,54 & 0,44 & 1,39 & 5,86 & 3,32 \\
\hline Sloanea guianensis & 12 & 0,85 & 11 & 1,22 & 0,87 & 2,77 & 4,84 & 3,62 \\
\hline Cabralea canjerana & 14 & 1 & 13 & 1,44 & 0,6 & 1,9 & 4,33 & 2,89 \\
\hline Ocotea dispersa & 18 & 1,28 & 15 & 1,66 & 0,34 & 1,07 & 4 & 2,35 \\
\hline Psychotria nuda & 22 & 1,57 & 19 & 2,1 & 0,08 & 0,24 & 3,91 & 1,81 \\
\hline Euterpe edulis & 20 & 1,42 & 16 & 1,77 & 0,11 & 0,36 & 3,55 & 1,78 \\
\hline Myrciaria floribunda & 10 & 0,71 & 10 & 1,1 & 0,37 & 1,19 & 3 & 1,9 \\
\hline Cyathea hirsuta & 26 & 1,85 & 7 & 0,77 & 0,11 & 0,35 & 2,97 & 2,2 \\
\hline Virola bicuhyba & 8 & 0,57 & 8 & 0,88 & 0,38 & 1,22 & 2,67 & 1,79 \\
\hline Cordia cf. superba & 12 & 0,85 & 11 & 1,22 & 0,17 & 0,55 & 2,61 & 1,4 \\
\hline Myrcia spectabilis & 13 & 0,93 & 13 & 1,44 & 0,07 & 0,24 & 2,6 & 1,16 \\
\hline Ocotea paranapiacabensis & 11 & 0,78 & 11 & 1,22 & 0,13 & 0,43 & 2,43 & 1,21 \\
\hline Campomanesia guaviroba & 11 & 0,78 & 9 & 0,99 & 0,14 & 0,44 & 2,22 & 1,23 \\
\hline Vernonia puberula & 11 & 0,78 & 6 & 0,66 & 0,24 & 0,76 & 2,21 & 1,55 \\
\hline Siparuna brasiliensis & 13 & 0,93 & 10 & 1,1 & 0,05 & 0,15 & 2,19 & 1,08 \\
\hline Cryptocarya saligna & 6 & 0,43 & 6 & 0,66 & 0,26 & 0,83 & 1,92 & 1,25 \\
\hline Nectandra membranacea & 6 & 0,43 & 4 & 0,44 & 0,29 & 0,93 & 1,8 & 1,36 \\
\hline Inga marginata & 5 & 0,36 & 4 & 0,44 & 0,31 & 1 & 1,8 & 1,36 \\
\hline Ardisia martiana & 9 & 0,64 & 9 & 0,99 & 0,03 & 0,08 & 1,72 & 0,72 \\
\hline Eugenia neoaustralis & 6 & 0,43 & 6 & 0,66 & 0,19 & 0,61 & 1,7 & 1,04 \\
\hline Miconia sp.1 & 8 & 0,57 & 8 & 0,88 & 0,05 & 0,15 & 1,6 & 0,72 \\
\hline Cyathea phalerata & 8 & 0,57 & 6 & 0,66 & 0,09 & 0,3 & 1,53 & 0,87 \\
\hline Coussarea meridionalis var. porophylla & 8 & 0,57 & 7 & 0,77 & 0,05 & 0,15 & 1,49 & 0,72 \\
\hline Marlierea sylvatica & 3 & 0,21 & 3 & 0,33 & 0,28 & 0,87 & 1,42 & 1,09 \\
\hline Marlierea tomentosa & 4 & 0,28 & 4 & 0,44 & 0,18 & 0,58 & 1,31 & 0,86 \\
\hline Syagrus pseudococos & 5 & 0,36 & 5 & 0,55 & 0,11 & 0,36 & 1,27 & 0,72 \\
\hline Terminalia januarensis & 3 & 0,21 & 3 & 0,33 & 0,23 & 0,72 & 1,27 & 0,93 \\
\hline Solanum sp.1 & 7 & 0,5 & 6 & 0,66 & 0,02 & 0,05 & 1,21 & 0,55 \\
\hline Alchornea sidifolia & 5 & 0,36 & 5 & 0,55 & 0,09 & 0,29 & 1,2 & 0,64 \\
\hline Solanum cf. bullatum & 6 & 0,43 & 6 & 0,66 & 0,03 & 0,08 & 1,17 & 0,51 \\
\hline Pseudopiptadenia leptostachya & 2 & 0,14 & 2 & 0,22 & 0,24 & 0,76 & 1,13 & 0,91 \\
\hline
\end{tabular}


Estudo do componente arbóreo em dois trechos de Mata Atlântica

Tabela 2. Continuação...

\begin{tabular}{|c|c|c|c|c|c|c|c|c|}
\hline Espécies & NInd & RelDe & AbsFr & RelFr & AbsDo & RelDo & IVI & IVC \\
\hline Coussarea accedens & 5 & 0,36 & 5 & 0,55 & 0,05 & 0,15 & 1,06 & 0,51 \\
\hline Calyptranthes lucida & 3 & 0,21 & 3 & 0,33 & 0,16 & 0,5 & 1,05 & 0,72 \\
\hline Zanthoxylum fagara & 3 & 0,21 & 3 & 0,33 & 0,16 & 0,5 & 1,05 & 0,71 \\
\hline Cupania oblongifolia & 5 & 0,36 & 5 & 0,55 & 0,04 & 0,13 & 1,04 & 0,49 \\
\hline Alseis floribunda & 5 & 0,36 & 5 & 0,55 & 0,03 & 0,1 & 1 & 0,45 \\
\hline Ocotea brachybotra & 5 & 0,36 & 5 & 0,55 & 0,03 & 0,09 & 1 & 0,45 \\
\hline Pourouma guianensis & 5 & 0,36 & 3 & 0,33 & 0,09 & 0,29 & 0,98 & 0,65 \\
\hline Solanum cf. swartizianum & 2 & 0,14 & 2 & 0,22 & 0,19 & 0,59 & 0,95 & 0,73 \\
\hline Ficus insipida & 4 & 0,28 & 4 & 0,44 & 0,07 & 0,23 & 0,95 & 0,51 \\
\hline Piper cernuum & 4 & 0,28 & 4 & 0,44 & 0,06 & 0,18 & 0,9 & 0,46 \\
\hline Piper gaudichaudianum & 5 & 0,36 & 4 & 0,44 & 0,01 & 0,04 & 0,84 & 0,4 \\
\hline Swartzia oblata & 3 & 0,21 & 3 & 0,33 & 0,09 & 0,28 & 0,82 & 0,49 \\
\hline Guarea macrophylla subsp. tuberculata & 4 & 0,28 & 4 & 0,44 & 0,02 & 0,08 & 0,8 & 0,36 \\
\hline Maytenus robusta & 1 & 0,07 & 1 & 0,11 & 0,2 & 0,62 & 0,8 & 0,69 \\
\hline Meriania calyptrata & 4 & 0,28 & 4 & 0,44 & 0,02 & 0,05 & 0,77 & 0,33 \\
\hline Eugenia prasina & 4 & 0,28 & 4 & 0,44 & 0,01 & 0,04 & 0,77 & 0,33 \\
\hline Cariniana estrellensis & 3 & 0,21 & 3 & 0,33 & 0,06 & 0,18 & 0,72 & 0,39 \\
\hline Eugenia monosperma & 2 & 0,14 & 2 & 0,22 & 0,11 & 0,34 & 0,7 & 0,48 \\
\hline Eugenia oblongata & 2 & 0,14 & 2 & 0,22 & 0,1 & 0,32 & 0,68 & 0,46 \\
\hline Endlicheria paniculata & 3 & 0,21 & 3 & 0,33 & 0,01 & 0,04 & 0,58 & 0,25 \\
\hline Piptadenia paniculata & 1 & 0,07 & 1 & 0,11 & 0,13 & 0,4 & 0,58 & 0,47 \\
\hline Rudgea jasminoides & 3 & 0,21 & 3 & 0,33 & 0,01 & 0,04 & 0,58 & 0,25 \\
\hline Myrcia sp.2 & 3 & 0,21 & 3 & 0,33 & 0,01 & 0,03 & 0,58 & 0,24 \\
\hline Citronella paniculata & 3 & 0,21 & 3 & 0,33 & 0,01 & 0,02 & 0,57 & 0,24 \\
\hline Tetrorchidium rubrivenium & 1 & 0,07 & 1 & 0,11 & 0,1 & 0,33 & 0,51 & 0,4 \\
\hline Citharexylum myrianthum & 1 & 0,07 & 1 & 0,11 & 0,1 & 0,32 & 0,5 & 0,39 \\
\hline Licaria armeniaca & 2 & 0,14 & 2 & 0,22 & 0,03 & 0,08 & 0,45 & 0,23 \\
\hline Eugenia tinguyensis & 2 & 0,14 & 2 & 0,22 & 0,02 & 0,06 & 0,43 & 0,21 \\
\hline Miconia dodecandra & 2 & 0,14 & 2 & 0,22 & 0,02 & 0,06 & 0,42 & 0,2 \\
\hline Eugenia cf. supraaxillaris & 1 & 0,07 & 1 & 0,11 & 0,08 & 0,24 & 0,42 & 0,31 \\
\hline Sapium biglandulosum & 2 & 0,14 & 2 & 0,22 & 0,02 & 0,05 & 0,41 & 0,19 \\
\hline Couepia venosa & 2 & 0,14 & 2 & 0,22 & 0,01 & 0,04 & 0,4 & 0,18 \\
\hline Psychotria birotula & 2 & 0,14 & 2 & 0,22 & 0,01 & 0,02 & 0,38 & 0,16 \\
\hline Ficus pulchella & 1 & 0,07 & 1 & 0,11 & 0,06 & 0,2 & 0,38 & 0,27 \\
\hline Maytenus sp.1 & 1 & 0,07 & 1 & 0,11 & 0,05 & 0,17 & 0,35 & 0,24 \\
\hline Coussapoa microcarpa & 1 & 0,07 & 1 & 0,11 & 0,05 & 0,17 & 0,35 & 0,24 \\
\hline Pterocarpus rohrii & 1 & 0,07 & 1 & 0,11 & 0,05 & 0,15 & 0,33 & 0,22 \\
\hline Aegiphila integrifolia & 1 & 0,07 & 1 & 0,11 & 0,04 & 0,11 & 0,3 & 0,18 \\
\hline Dendropanax cuneatus & 1 & 0,07 & 1 & 0,11 & 0,03 & 0,11 & 0,29 & 0,18 \\
\hline Schefflera calva & 1 & 0,07 & 1 & 0,11 & 0,03 & 0,09 & 0,27 & 0,16 \\
\hline Leandra dasytricha & 2 & 0,14 & 1 & 0,11 & 0 & 0,01 & 0,27 & 0,16 \\
\hline Rapanea ferruginea & 1 & 0,07 & 1 & 0,11 & 0,03 & 0,08 & 0,26 & 0,15 \\
\hline Schefflera angustissima & 1 & 0,07 & 1 & 0,11 & 0,02 & 0,07 & 0,25 & 0,14 \\
\hline Miconia cinnamomifolia & 1 & 0,07 & 1 & 0,11 & 0,01 & 0,03 & 0,22 & 0,11 \\
\hline Calyptranthes grandifolia & 1 & 0,07 & 1 & 0,11 & 0,01 & 0,03 & 0,21 & 0,1 \\
\hline Vernonia sp. & 1 & 0,07 & 1 & 0,11 & 0,01 & 0,03 & 0,21 & 0,1 \\
\hline indeterminada sp.1 & 1 & 0,07 & 1 & 0,11 & 0,01 & 0,02 & 0,21 & 0,1 \\
\hline Guatteria australis & 1 & 0,07 & 1 & 0,11 & 0,01 & 0,02 & 0,2 & 0,09 \\
\hline Casearia sylvestris & 1 & 0,07 & 1 & 0,11 & 0 & 0,02 & 0,2 & 0,09 \\
\hline Cecropia pachystachya & 1 & 0,07 & 1 & 0,11 & 0 & 0,01 & 0,2 & 0,09 \\
\hline Miconia tristis & 1 & 0,07 & 1 & 0,11 & 0 & 0,01 & 0,19 & 0,08 \\
\hline
\end{tabular}


Ramos, E. et al.

Tabela 2. Continuação...

\begin{tabular}{lcccccccc}
\hline \multicolumn{1}{c}{ Espécies } & NInd & RelDe & AbsFr & RelFr & AbsDo & RelDo & IVI & IVC \\
\hline Urera baccifera & 1 & 0,07 & 1 & 0,11 & 0 & 0,01 & 0,19 & 0,08 \\
Zollernia ilicifolia & 1 & 0,07 & 1 & 0,11 & 0 & 0,01 & 0,19 & 0,08 \\
Piper rivinoides & 1 & 0,07 & 1 & 0,11 & 0 & 0,01 & 0,19 & 0,08 \\
Quiina glaziovii & 1 & 0,07 & 1 & 0,11 & 0 & 0,01 & 0,19 & 0,08 \\
Allophylus petiolulatus & 1 & 0,07 & 1 & 0,11 & 0 & 0,01 & 0,19 & 0,08 \\
Coccoloba glaziovii & 1 & 0,07 & 1 & 0,11 & 0 & 0,01 & 0,19 & 0,08 \\
Ficus obtusiuscula & 1 & 0,07 & 1 & 0,11 & 0 & 0,01 & 0,19 & 0,08 \\
\hline
\end{tabular}

Tabela 3. Espécies amostradas aos 200 m de altitude na Fazenda Capricórnio, Ubatuba, PESM (SP) e seus respectivos parâmetros fitossociológicos, em ordem decrescente de IVI. NI= número de indivíduos; DR = dominância relativa; FA = frequiência absoluta; FR freqüência relativa; DoA = dominância absoluta; DoR dominância relativa; IVC = índice de valor e cobertura; IVI = índice de valor de importância.

Table 3. Sampled species at $200 \mathrm{~m}$ altitude in Capricórnio Farm, Ubatuba, PESM (SP) and their quantitative parameters ordered in decreasingly values of VI. $\mathrm{NI}=$ individual numbers; $\mathrm{DR}=$ relative dominance; FA = absolute frequency $; \mathrm{FR}=$ relative frequence; DoA = absolute dominance; DoR = relative dominance; IVC = coverage value index; IVI = importance value index.

\begin{tabular}{|c|c|c|c|c|c|c|c|c|}
\hline Espécies & NInd & RelDe & AbsFr & RelFr & AbsDo & RelDo & IVI & IVC \\
\hline Rudgea jasminoides & 148 & 9,27 & 76 & 6,26 & 0,9 & 2,34 & 17,86 & 11,61 \\
\hline Euterpe edulis & 144 & 9,02 & 72 & 5,93 & 0,7 & 1,82 & 16,76 & 10,83 \\
\hline Mortas & 69 & 4,32 & 47 & 3,87 & 3,16 & 8,25 & 16,44 & 12,57 \\
\hline Eriotheca pentaphylla & 42 & 2,63 & 32 & 2,63 & 3,35 & 8,76 & 14,02 & 11,39 \\
\hline Guapira opposita & 52 & 3,19 & 36 & 2,96 & 2,02 & 5,29 & 11,44 & 8,48 \\
\hline Mollinedia schottiana & 74 & 4,63 & 48 & 3,95 & 0,5 & 1,29 & 9,88 & 5,93 \\
\hline Coussarea meridionalis var. porophylla & 65 & 4,07 & 47 & 3,87 & 0,43 & 1,11 & 9,05 & 5,18 \\
\hline Syagrus pseudococos & 48 & 3,01 & 32 & 2,63 & 0,9 & 2,36 & 8 & 5,37 \\
\hline Eugenia prasina & 58 & 3,63 & 41 & 3,37 & 0,27 & 0,7 & 7,71 & 4,33 \\
\hline Sloanea guianensis & 19 & 1,19 & 18 & 1,48 & 1,84 & 4,81 & 7,48 & 6 \\
\hline Coussarea accedens & 52 & 3,26 & 38 & 3,13 & 0,36 & 0,94 & 7,32 & 4,2 \\
\hline Bathysa australis & 41 & 2,57 & 29 & 2,39 & 0,74 & 1,92 & 6,88 & 4,49 \\
\hline Chrysophyllum flexuosum & 36 & 2,25 & 30 & 2,47 & 0,59 & 1,54 & 6,26 & 3,79 \\
\hline Bathysa mendoncaei & 40 & 2,5 & 29 & 2,39 & 0,51 & 1,32 & 6,21 & 3,83 \\
\hline Cordia taguahyensis & 33 & 2,07 & 29 & 2,39 & 0,43 & 1,13 & 5,58 & 3,2 \\
\hline Garcinia gardneriana & 28 & 1,75 & 23 & 1,89 & 0,66 & 1,74 & 5,38 & 3,49 \\
\hline Marlierea tomentosa & 29 & 1,82 & 23 & 1,89 & 0,6 & 1,56 & 5,27 & 3,38 \\
\hline Ardisia martiana & 33 & 2,07 & 30 & 2,47 & 0,13 & 0,34 & 4,88 & 2,41 \\
\hline Cryptocarya mandioccana & 12 & 0,75 & 10 & 0,82 & 1,18 & 3,07 & 4,64 & 3,82 \\
\hline Myrciaria floribunda & 27 & 1,69 & 24 & 1,98 & 0,37 & 0,97 & 4,63 & 2,66 \\
\hline Pouteria psammophila & 11 & 0,69 & 11 & 0,91 & 1,06 & 2,78 & 4,37 & 3,47 \\
\hline Eugenia oblongata & 17 & 1,06 & 14 & 1,15 & 0,53 & 1,39 & 3,61 & 2,46 \\
\hline Alchornea triplinervia & 7 & 0,44 & 6 & 0,49 & 0,94 & 2,45 & 3,39 & 2,89 \\
\hline Ocotea dispersa & 15 & 0,94 & 14 & 1,15 & 0,31 & 0,8 & 2,89 & 1,74 \\
\hline Calyptranthes lucida & 13 & 0,81 & 12 & 0,99 & 0,32 & 0,85 & 2,65 & 1,66 \\
\hline Micropholis crassipedicellata & 7 & 0,44 & 7 & 0,58 & 0,62 & 1,62 & 2,63 & 2,06 \\
\hline Rapanea hermogenesii & 13 & 0,81 & 13 & 1,07 & 0,25 & 0,65 & 2,53 & 1,46 \\
\hline Mollinedia oligantha & 14 & 0,88 & 11 & 0,91 & 0,17 & 0,45 & 2,23 & 1,32 \\
\hline Coиepia venosa & 9 & 0,56 & 8 & 0,66 & 0,37 & 0,97 & 2,19 & 1,54 \\
\hline Faramea pachyantha & 6 & 0,38 & 6 & 0,49 & 0,47 & 1,24 & 2,11 & 1,62 \\
\hline Rudgea vellerea & 14 & 0,88 & 11 & 0,91 & 0,12 & 0,32 & 2,1 & 1,19 \\
\hline Hyeronima alchorneoides & 3 & 0,19 & 3 & 0,25 & 0,64 & 1,66 & 2,1 & 1,85 \\
\hline Ouratea parviflora & 14 & 0,88 & 13 & 1,07 & 0,04 & 0,11 & 2,06 & 0,99 \\
\hline Swartzia langsdorffii & 5 & 0,31 & 4 & 0,33 & 0,53 & 1,39 & 2,04 & 1,71 \\
\hline Terminalia januarensis & 6 & 0,38 & 6 & 0,49 & 0,43 & 1,12 & 1,99 & 1,49 \\
\hline Mollinedia boracensis & 10 & 0,63 & 9 & 0,74 & 0,22 & 0,57 & 1,93 & 1,19 \\
\hline
\end{tabular}


Estudo do componente arbóreo em dois trechos de Mata Atlântica

Tabela 3. Continuação...

\begin{tabular}{|c|c|c|c|c|c|c|c|c|}
\hline Espécies & NInd & RelDe & AbsFr & RelFr & AbsDo & RelDo & IVI & IVC \\
\hline Psychotria nuda & 14 & 0,87 & 13 & 1,07 & 0,04 & 0,11 & 2,4 & 0,98 \\
\hline Citronella paniculata & 10 & 0,63 & 9 & 0,74 & 0,2 & 0,53 & 1,9 & 1,16 \\
\hline Myrcia sp.3 & 15 & 0,94 & 10 & 0,82 & 0,04 & 0,11 & 1,88 & 1,05 \\
\hline Pouteria caimito & 5 & 0,31 & 5 & 0,41 & 0,43 & 1,12 & 1,84 & 1,43 \\
\hline Schefflera angustissima & 7 & 0,44 & 6 & 0,49 & 0,34 & 0,89 & 1,82 & 1,33 \\
\hline Copaifera langsdorffii & 6 & 0,38 & 6 & 0,49 & 0,36 & 0,93 & 1,8 & 1,31 \\
\hline Malouetia arborea & 4 & 0,25 & 4 & 0,33 & 0,44 & 1,16 & 1,74 & 1,41 \\
\hline Virola bicuhyba & 5 & 0,31 & 5 & 0,41 & 0,36 & 0,94 & 1,66 & 1,25 \\
\hline Astrocaryum aculeatissimum & 10 & 0,63 & 9 & 0,74 & 0,09 & 0,25 & 1,61 & 0,87 \\
\hline Licania hoehnei & 5 & 0,31 & 5 & 0,41 & 0,32 & 0,84 & 1,56 & 1,15 \\
\hline Myrceugenia myrcioides & 10 & 0,63 & 8 & 0,66 & 0,1 & 0,25 & 1,54 & 0,88 \\
\hline Tachigali denudata & 5 & 0,31 & 5 & 0,41 & 0,28 & 0,72 & 1,45 & 1,04 \\
\hline Eugenia neoaustralis & 10 & 0,63 & 7 & 0,58 & 0,09 & 0,23 & 1,44 & 0,86 \\
\hline Eugenia excelsa & 10 & 0,63 & 8 & 0,66 & 0,06 & 0,15 & 1,43 & 0,78 \\
\hline Hymenaea courbaril var. altissima & 2 & 0,13 & 2 & 0,16 & 0,43 & 1,13 & 1,42 & 1,25 \\
\hline Dahlstedtia pinnata & 9 & 0,56 & 9 & 0,74 & 0,03 & 0,08 & 1,39 & 0,65 \\
\hline Cupania oblongifolia & 4 & 0,25 & 4 & 0,33 & 0,29 & 0,76 & 1,34 & 1,01 \\
\hline Tetrastylidium grandifolium & 5 & 0,31 & 5 & 0,41 & 0,23 & 0,61 & 1,33 & 0,92 \\
\hline Cupania furfuracea & 5 & 0,31 & 5 & 0,41 & 0,22 & 0,58 & 1,3 & 0,89 \\
\hline Mabea piriri & 3 & 0,19 & 3 & 0,25 & 0,33 & 0,86 & 1,29 & 1,05 \\
\hline Eugenia cf. bocainensis & 6 & 0,38 & 6 & 0,49 & 0,16 & 0,42 & 1,29 & 0,8 \\
\hline Eugenia cf. supraaxillaris & 2 & 0,13 & 2 & 0,16 & 0,38 & 1 & 1,29 & 1,12 \\
\hline Guarea macrophylla subsp. tuberculata & 7 & 0,44 & 6 & 0,49 & 0,13 & 0,35 & 1,28 & 0,79 \\
\hline Posoqueria latifólia & 6 & 0,38 & 6 & 0,49 & 0,15 & 0,39 & 1,26 & 0,77 \\
\hline Pausandra morisiana & 8 & 0,5 & 5 & 0,41 & 0,13 & 0,34 & 1,25 & 0,84 \\
\hline Eugenia monosperma & 7 & 0,44 & 6 & 0,49 & 0,12 & 0,3 & 1,24 & 0,74 \\
\hline Maytenus ubatubensis & 8 & 0,5 & 7 & 0,58 & 0,03 & 0,09 & 1,16 & 0,59 \\
\hline Mollinedia lamprophylla & 6 & 0,38 & 6 & 0,49 & 0,11 & 0,28 & 1,15 & 0,66 \\
\hline Eugenia subavenia & 7 & 0,44 & 7 & 0,58 & 0,03 & 0,08 & 1,09 & 0,51 \\
\hline Coussapoa microcarpa & 2 & 0,13 & 2 & 0,16 & 0,29 & 0,77 & 1,06 & 0,89 \\
\hline Cabralea canjerana & 1 & 0,06 & 1 & 0,08 & 0,35 & 0,91 & 1,06 & 0,97 \\
\hline Sorocea hilarii & 6 & 0,38 & 5 & 0,41 & 0,1 & 0,26 & 1,05 & 0,64 \\
\hline Mouriri chamissoana & 2 & 0,13 & 2 & 0,16 & 0,28 & 0,73 & 1,02 & 0,85 \\
\hline Lecythis cf. lanceolata & 2 & 0,13 & 2 & 0,16 & 0,27 & 0,72 & 1,01 & 0,84 \\
\hline Sapium biglandulosum & 2 & 0,13 & 2 & 0,16 & 0,27 & 0,71 & 1 & 0,83 \\
\hline Neomitranthes glomerata & 4 & 0,25 & 4 & 0,33 & 0,16 & 0,42 & 1 & 0,67 \\
\hline Buchenavia kleinii & 1 & 0,06 & 1 & 0,08 & 0,32 & 0,84 & 0,99 & 0,9 \\
\hline Calyptranthes strigipes & 5 & 0,31 & 5 & 0,41 & 0,1 & 0,25 & 0,98 & 0,57 \\
\hline Cryptocarya saligna & 4 & 0,25 & 4 & 0,33 & 0,13 & 0,34 & 0,91 & 0,59 \\
\hline Zollernia ilicifolia & 4 & 0,25 & 4 & 0,33 & 0,1 & 0,27 & 0,85 & 0,52 \\
\hline Cecropia glaziovii & 5 & 0,31 & 3 & 0,25 & 0,11 & 0,28 & 0,84 & 0,59 \\
\hline Jacaratia spinosa & 4 & 0,25 & 3 & 0,25 & 0,13 & 0,33 & 0,83 & 0,58 \\
\hline Marlierea sylvatica & 2 & 0,13 & 2 & 0,16 & 0,18 & 0,48 & 0,77 & 0,61 \\
\hline Marlierea racemosa & 3 & 0,19 & 3 & 0,25 & 0,12 & 0,33 & 0,76 & 0,51 \\
\hline Myrcia pubipetala & 3 & 0,19 & 3 & 0,25 & 0,11 & 0,29 & 0,73 & 0,48 \\
\hline Cyathea phalerata & 4 & 0,25 & 4 & 0,33 & 0,04 & 0,1 & 0,68 & 0,35 \\
\hline Marlierea glazioviana & 4 & 0,25 & 4 & 0,33 & 0,04 & 0,09 & 0,67 & 0,34 \\
\hline Salacia grandifolia & 4 & 0,25 & 4 & 0,33 & 0,03 & 0,07 & 0,65 & 0,33 \\
\hline Lonchocarpus cultratus & 2 & 0,13 & 2 & 0,16 & 0,14 & 0,36 & 0,65 & 0,48 \\
\hline Licaria armeniaca & 3 & 0,19 & 3 & 0,25 & 0,08 & 0,21 & 0,64 & 0,39 \\
\hline Schefflera calva & 4 & 0,25 & 4 & 0,33 & 0,02 & 0,06 & 0,64 & 0,31 \\
\hline
\end{tabular}


Ramos, E. et al.

Tabela 3. Continuação...

\begin{tabular}{|c|c|c|c|c|c|c|c|c|}
\hline Espécies & NInd & RelDe & AbsFr & RelFr & AbsDo & RelDo & IVI & IVC \\
\hline Quararibea turbinata & 4 & 0,25 & 4 & 0,33 & 0,01 & 0,04 & 0,62 & 0,29 \\
\hline Guatteria australis & 3 & 0,19 & 3 & 0,25 & 0,07 & 0,18 & 0,62 & 0,37 \\
\hline Aegiphila integrifolia & 3 & 0,19 & 2 & 0,16 & 0,1 & 0,26 & 0,62 & 0,45 \\
\hline Psychotria birotula & 4 & 0,25 & 4 & 0,33 & 0,01 & 0,03 & 0,61 & 0,28 \\
\hline Campomanesia laurifolia & 4 & 0,25 & 3 & 0,25 & 0,03 & 0,08 & 0,58 & 0,33 \\
\hline Ecclinusa ramiflora & 2 & 0,13 & 2 & 0,16 & 0,11 & 0,29 & 0,58 & 0,41 \\
\hline Myrcia richardiana & 3 & 0,19 & 3 & 0,25 & 0,05 & 0,12 & 0,55 & 0,31 \\
\hline Pouteria aff. torta & 1 & 0,06 & 1 & 0,08 & 0,15 & 0,4 & 0,54 & 0,46 \\
\hline Maytenus sp.3 & 1 & 0,06 & 1 & 0,08 & 0,15 & 0,39 & 0,53 & 0,45 \\
\hline Swartzia oblata & 2 & 0,13 & 2 & 0,16 & 0,09 & 0,24 & 0,53 & 0,37 \\
\hline Bathysa stipulata & 3 & 0,19 & 3 & 0,25 & 0,03 & 0,09 & 0,53 & 0,28 \\
\hline Pouteria sp. 2 & 3 & 0,19 & 3 & 0,25 & 0,03 & 0,09 & 0,52 & 0,28 \\
\hline Eugenia cerasiflora & 3 & 0,19 & 3 & 0,25 & 0,03 & 0,08 & 0,52 & 0,27 \\
\hline Endlicheria paniculata & 3 & 0,19 & 3 & 0,25 & 0,02 & 0,05 & 0,49 & 0,24 \\
\hline Guapira hirsuta & 2 & 0,13 & 2 & 0,16 & 0,07 & 0,19 & 0,48 & 0,32 \\
\hline Eugenia multicostata & 3 & 0,19 & 3 & 0,25 & 0,02 & 0,04 & 0,48 & 0,23 \\
\hline Alsophila sternbergii & 2 & 0,13 & 2 & 0,16 & 0,05 & 0,14 & 0,43 & 0,27 \\
\hline Tabebuia serratifolia & 2 & 0,13 & 2 & 0,16 & 0,05 & 0,13 & 0,42 & 0,26 \\
\hline Eugenia involucrata & 1 & 0,06 & 1 & 0,08 & 0,1 & 0,27 & 0,41 & 0,33 \\
\hline Miconia tristis & 3 & 0,19 & 2 & 0,16 & 0,02 & 0,04 & 0,4 & 0,23 \\
\hline Pouteria sp.1 & 1 & 0,06 & 1 & 0,08 & 0,09 & 0,24 & 0,39 & 0,3 \\
\hline Maytenus robusta & 1 & 0,06 & 1 & 0,08 & 0,09 & 0,23 & 0,37 & 0,29 \\
\hline Symplocos variabilis & 2 & 0,13 & 2 & 0,16 & 0,03 & 0,08 & 0,37 & 0,21 \\
\hline Henriettella glabra & 1 & 0,06 & 1 & 0,08 & 0,08 & 0,22 & 0,36 & 0,28 \\
\hline cf. Chomelia pohliana & 1 & 0,06 & 1 & 0,08 & 0,08 & 0,21 & 0,35 & 0,27 \\
\hline Heisteria silvianii & 2 & 0,13 & 2 & 0,16 & 0,02 & 0,06 & 0,35 & 0,18 \\
\hline Myrocarpus frondosus & 2 & 0,13 & 2 & 0,16 & 0,02 & 0,05 & 0,34 & 0,18 \\
\hline Alseis floribunda & 2 & 0,13 & 2 & 0,16 & 0,02 & 0,05 & 0,34 & 0,17 \\
\hline Pseudopiptadenia leptostachya & 2 & 0,13 & 2 & 0,16 & 0,02 & 0,04 & 0,33 & 0,17 \\
\hline Alchornea glandulosa & 2 & 0,13 & 2 & 0,16 & 0,02 & 0,04 & 0,33 & 0,17 \\
\hline Daphnopsis schwackeana & 2 & 0,13 & 2 & 0,16 & 0,01 & 0,04 & 0,33 & 0,16 \\
\hline Randia sp.1 & 2 & 0,13 & 2 & 0,16 & 0,01 & 0,03 & 0,32 & 0,15 \\
\hline Allophylus petiolulatus & 2 & 0,13 & 2 & 0,16 & 0,01 & 0,02 & 0,31 & 0,15 \\
\hline Eugenia mosenii & 2 & 0,13 & 2 & 0,16 & 0,01 & 0,02 & 0,31 & 0,14 \\
\hline Miconia sp.1 & 2 & 0,13 & 2 & 0,16 & 0,01 & 0,02 & 0,31 & 0,14 \\
\hline Ocotea teleiandra & 2 & 0,13 & 2 & 0,16 & 0 & 0,01 & 0,3 & 0,14 \\
\hline Protium kleinii & 1 & 0,06 & 1 & 0,08 & 0,06 & 0,15 & 0,3 & 0,21 \\
\hline Ocotea tabacifolia & 1 & 0,06 & 1 & 0,08 & 0,06 & 0,15 & 0,29 & 0,21 \\
\hline Miconia cabucu & 1 & 0,06 & 1 & 0,08 & 0,05 & 0,13 & 0,27 & 0,19 \\
\hline Magnolia ovata & 1 & 0,06 & 1 & 0,08 & 0,05 & 0,12 & 0,27 & 0,18 \\
\hline Rustia formosa & 1 & 0,06 & 1 & 0,08 & 0,04 & 0,11 & 0,26 & 0,17 \\
\hline Inga edulis & 1 & 0,06 & 1 & 0,08 & 0,04 & 0,1 & 0,24 & 0,16 \\
\hline Miconia cf. picinguabensis & 2 & 0,13 & 1 & 0,08 & 0,01 & 0,03 & 0,24 & 0,15 \\
\hline indeterminada sp. 3 & 1 & 0,06 & 1 & 0,08 & 0,03 & 0,09 & 0,23 & 0,15 \\
\hline Eugenia batingabranca & 1 & 0,06 & 1 & 0,08 & 0,03 & 0,08 & 0,22 & 0,14 \\
\hline Tontelea aff. fluminensis & 1 & 0,06 & 1 & 0,08 & 0,03 & 0,07 & 0,21 & 0,13 \\
\hline Myrcia sp.4 & 1 & 0,06 & 1 & 0,08 & 0,02 & 0,05 & 0,19 & 0,11 \\
\hline Marlierea suaveolens & 1 & 0,06 & 1 & 0,08 & 0,02 & 0,05 & 0,19 & 0,11 \\
\hline Randia sp.2 & 1 & 0,06 & 1 & 0,08 & 0,01 & 0,04 & 0,18 & 0,1 \\
\hline Pourouma guianensis & 1 & 0,06 & 1 & 0,08 & 0,01 & 0,03 & 0,18 & 0,1 \\
\hline Rollinia dolabripetala & 1 & 0,06 & 1 & 0,08 & 0,01 & 0,03 & 0,17 & 0,09 \\
\hline
\end{tabular}


Tabela 3. Continuação...

\begin{tabular}{lcccccccc}
\hline \multicolumn{1}{c}{ Espécies } & NInd & RelDe & AbsFr & RelFr & AbsDo & RelDo & IVI & IVC \\
\hline Calyptranthes lanceolata & 1 & 0,06 & 1 & 0,08 & 0,01 & 0,03 & 0,17 & 0,09 \\
Hirtella hebeclada & 1 & 0,06 & 1 & 0,08 & 0,01 & 0,02 & 0,16 & 0,08 \\
Ilex theezans & 1 & 0,06 & 1 & 0,08 & 0 & 0,01 & 0,16 & 0,07 \\
Casearia sylvestris & 1 & 0,06 & 1 & 0,08 & 0 & 0,01 & 0,16 & 0,07 \\
Mollinedia uleana & 1 & 0,06 & 1 & 0,08 & 0 & 0,01 & 0,16 & 0,07 \\
Leandra dasytricha & 1 & 0,06 & 1 & 0,08 & 0 & 0,01 & 0,15 & 0,07 \\
Eugenia cuprea & 1 & 0,06 & 1 & 0,08 & 0 & 0,01 & 0,15 & 0,07 \\
Matayba intermedia & 1 & 0,06 & 1 & 0,08 & 0 & 0,01 & 0,15 & 0,07 \\
Inga grazielae & 1 & 0,06 & 1 & 0,08 & 0 & 0,01 & 0,15 & 0,07 \\
Brosimum lactescens & 1 & 0,06 & 1 & 0,08 & 0 & 0,01 & 0,15 & 0,07 \\
Inga capitata & 1 & 0,06 & 1 & 0,08 & 0 & 0,01 & 0,15 & 0,07 \\
indeterminada sp.4 & 1 & 0,06 & 1 & 0,08 & 0 & 0,01 & 0,15 & 0,07 \\
Meriania calyptrata & 1 & 0,06 & 1 & 0,08 & 0 & 0 & 0,15 & 0,07 \\
Coutarea hexandra & 1 & 0,06 & 1 & 0,08 & 0 & 0 & 0,15 & 0,07 \\
indeterminada sp.2 & 1 & 0,06 & 1 & 0,08 & 0 & 0 & 0,15 & 0,07 \\
\hline
\end{tabular}

pode ser citada a altura máxima atingida pelos indivíduos, que em outros locais pode chegar até $25 \mathrm{~m}$ (Reitz 1974). O mesmo se dá na parcela $\mathrm{H}$, onde os indivíduos atingem no máximo $13 \mathrm{~m}$ de altura, e a maioria (79\%) tem de 4 a $8 \mathrm{~m}$.

Na parcela F o índice de diversidade de Shannon (H') foi de 3,56 e o índice de equabilidade de Pielou (J), de 0,76. Na parcela H o valor de $\mathrm{H}^{\prime}$ foi de 4,05 e o J, de 0,80 . Os dois trechos diferiram com respeito à diversidade ao nível de $0,05 \%(\mathrm{p}<0,0001)$. Houve diferença entre os $H^{\prime}$ dos dois trechos $\left(\mathrm{t}_{\text {modificado }}=9,5347 ; \mathrm{p}<0.05\right)$, o que já era esperado devido ao ambiente mais perturbado apresentado pelo trecho mais baixo. O Índice de Simpson (C) (0,032 para a parcela H e 0,056 para a parcela F) mostram que a diferença de diversidade ocorre devido à maior dominância de algumas espécies.

As análises multivariadas indicaram separação entre os dois trechos, e com o dendrograma de similaridade reconhecemos a formação de dois blocos florísticos, tanto para a matriz de presença ou ausência quanto para a quantitativa (Figura 4). A parcela $\mathrm{H}$ apresentou maior diversidade, e podemos sugerir que este fato se deve, pelo menos em parte, ao menor grau de perturbação. Para a matriz binária a similaridade de Jaccard foi de 0,55 e a correlação cofenética foi de 0,69 , enquanto para a matriz quantitativa o coeficiente de Bray Curtis foi de 0,29 e a correlação cofenética foi de 0,72 .

A ordenação por PCO binária também separou os trechos estudados; na matriz binária o primeiro eixo explica 7,19\% da variância total dos dados, enquanto o segundo explica apenas 2,69\% dessa variância. Na matriz quantitativa o primeiro eixo explica $14,34 \%$ da variância e o segundo 4,48\% (Figura 5). A análise TWINSPAN separou quase todas as subparcelas dos trechos em sua primeira divisão tanto na matriz de presença e ausência (autovalor: 0,54 ) quanto na matriz quantitativa (autovalor: 0,58), e as espécies indicadoras para a parcela $\mathrm{F}$ foram Bathysa australis, Lonchocarpus cultratus, Alsophila sternbergii e, para a parcela $\mathrm{H}$, Rudgea jasminoides, Euterpe edulis, Coussarea meridionalis e Eugenia prasina.

A Tabela 1 apresenta ainda dados referentes à raridade das espécies amostradas neste estudo. De todas as espécies analisadas nos trechos, $55 \%$ foram localmente abundantes e $45 \%$ foram escassas, com apenas um ou dois indivíduos; $81 \%$ das espécies ocorrentes nos dois trechos são ocasionais ou comuns, segundo Moreira (2007), com um até 10 indivíduos. Oitenta e quatro destas espécies também ocorreram com baixa frequiência em outros estudos de mesma fisionomia. De todas as espécies ocorrentes nos dois trechos, 119 constam na análise de Caiafa \& Martins (2010), das quais $75 \%$ são espécies comuns. Ainda segundo aqueles autores, foram encontradas cinco formas de raridade para 29 espécies deste trabalho. Uma proporção de $2,1 \%$ (quatro espécies) foi rara devido a populações escassas, distribuição geográfica ampla e ocorrência em vários hábitats (forma 1). Já 9,4\% (18 espécies) foram raras devido a populações abundantes, distribuição geográfica restrita e ocorrência em vários hábitats, enquanto 2,6\% (cinco espécies) foram raras devido à populações escassas, distribuição restrita e ocorrência em vários hábitats (forma 5). Uma espécie foi rara pois é localmente abundante, com distribuição restrita e hábitat preferencial (forma 6), e outra por ser escassa, ter distribuição restrita e hábitat preferencial (forma 7). Entre as espécies classificadas, não foram encontradas espécies raras quanto ao hábitat preferencial, populações abundantes e ampla distribuição (forma 2), nem quanto populações escassas, hábitat único e ampla distribuição (forma 3). Das espécies amostradas, cinco encontram-se na categoria quase ameaçadas (QA), e cinco na vulnerável (VU); 105 são endêmicas do Brasil, 90 ocorrem apenas na Mata Atlântica e 51 têm distribuição restrita, ocorrendo somente em ambientes de Floresta Ombrófila Densa. Das espécies endêmicas, 38 ocorrem em ambos os trechos, 12 ocorrem somente na parcela $\mathrm{F}$ e 50 ocorrem somente na parcela $\mathrm{H}$.

\section{Discussão}

Os dois trechos são bastante singulares, sendo que a parcela $\mathrm{H}$ destaca-se pela riqueza. Uma vez que o declínio de espécies está intimamente associado às atividades antrópicas (Hero \& Ridgway 2006), e considerando que a retirada seletiva de madeira pode causar alterações na estrutura das florestas e estar associada a baixos índices de diversidade (Borém \& Oliveira-Filho 2002, Neves \& Peixoto 2008), a perturbação da área deve ser considerada como relevante nas comparações florísticas (Carvalho et al. 2006). Reflexos das atividades antrópicas, como a fragmentação florestal, por exemplo, vêm sendo detectados em comunidades e populações vegetais, variando de alterações na composição e riqueza de espécies (Bernacci et al. 2006) a perdas de variabilidade genética por deriva (Seoane et al. 2000). Considerando que efeitos como estes podem levar as espécies 
Ramos, E. et al.

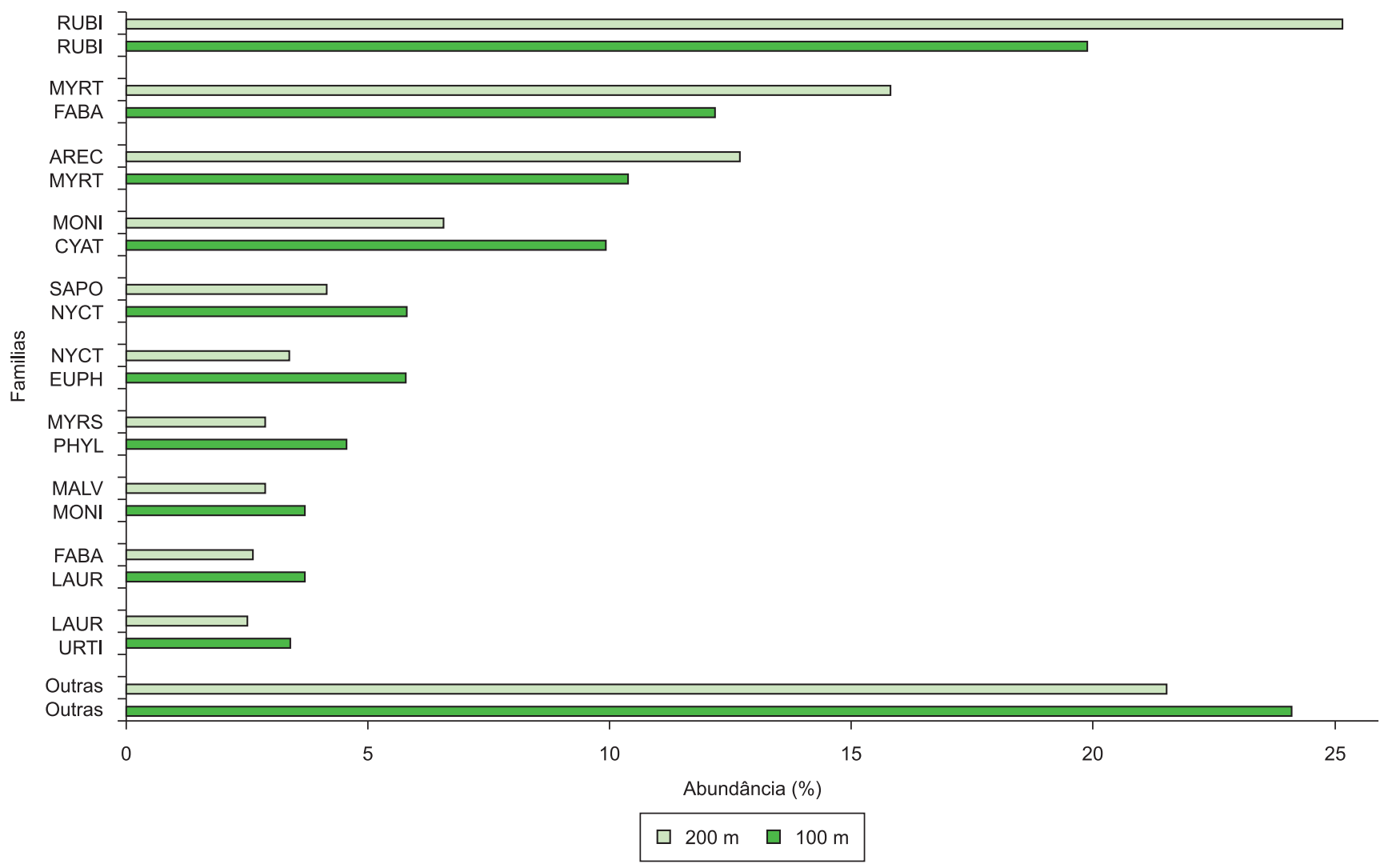

Figura 1. Famílias mais abundantes dos indivíduos com pelo menos $15 \mathrm{~cm}$ de perímetro de tronco (a 1,30 $\mathrm{m}$ do solo) amostrados em dois trechos de Floresta Ombrófila Densa Submonana (100 e 200 m de altitude) na Fazenda Capricórnio (Ubatuba, SP).

Figure 1. More abundant families of individuals with at least $15 \mathrm{~cm}$ perimeter (1,30 m beyond ground) sampled in two areas of Submontane Rainforest (at 100 and 200 m altitude) in Capricórnio Farm (Ubatuba, SP).

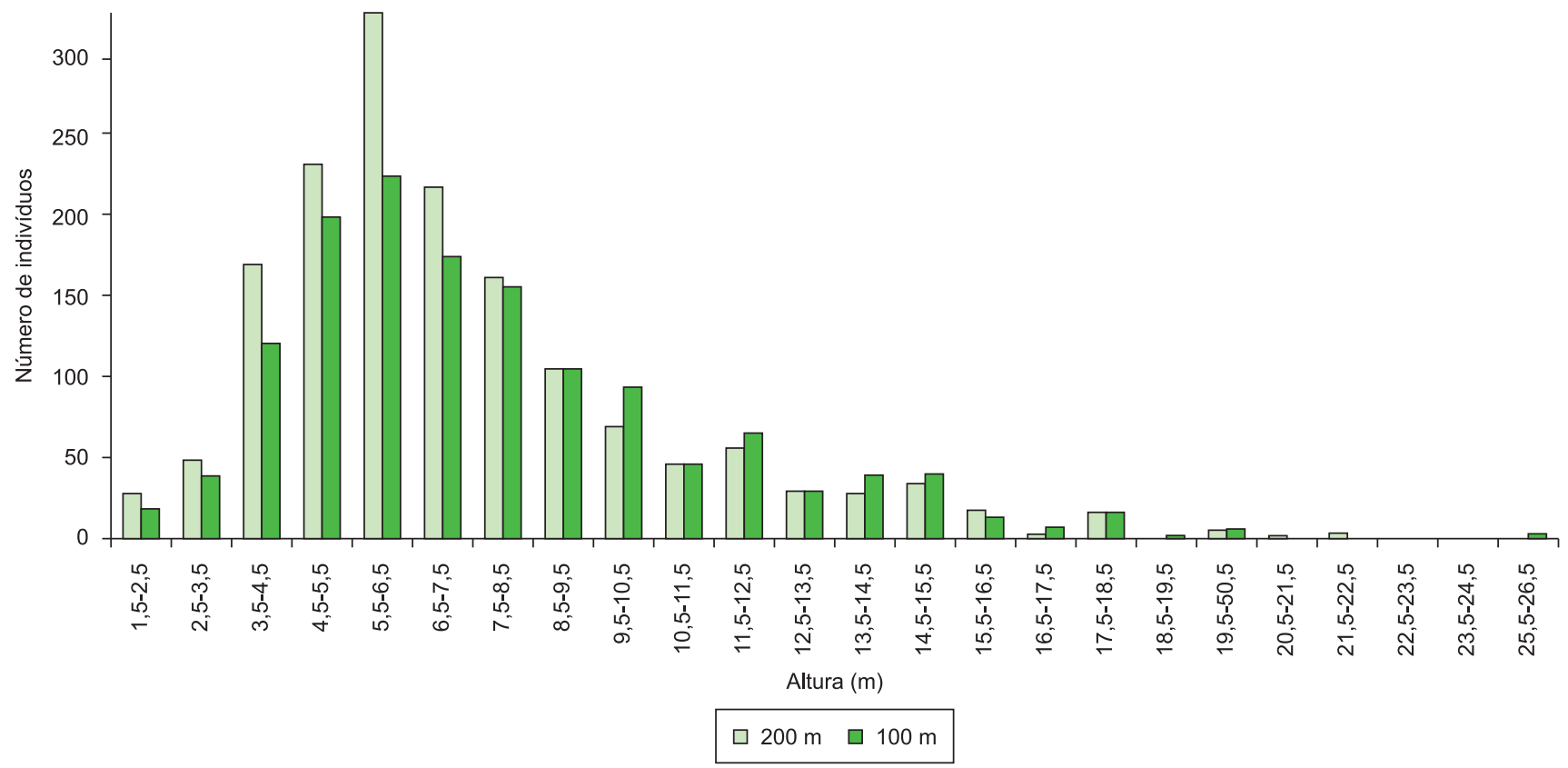

Figura 2. Classes de altura dos indivíduos com pelo menos $15 \mathrm{~cm}$ de perímetro de tronco (a 1,30 m do solo) amostrados em dois trechos de Floresta Ombrófila Densa Submonana (100 e $200 \mathrm{~m}$ de altitude) na Fazenda Capricórnio (Ubatuba, SP).

Figure 2. Height classes of individuals with at least $15 \mathrm{~cm}$ perimeter $(1,30 \mathrm{~m}$ beyond ground) sampled in two areas of Submontane Rainforest (at 100 and $200 \mathrm{~m}$ altitude) in Capricórnio Farm (Ubatuba, SP). 


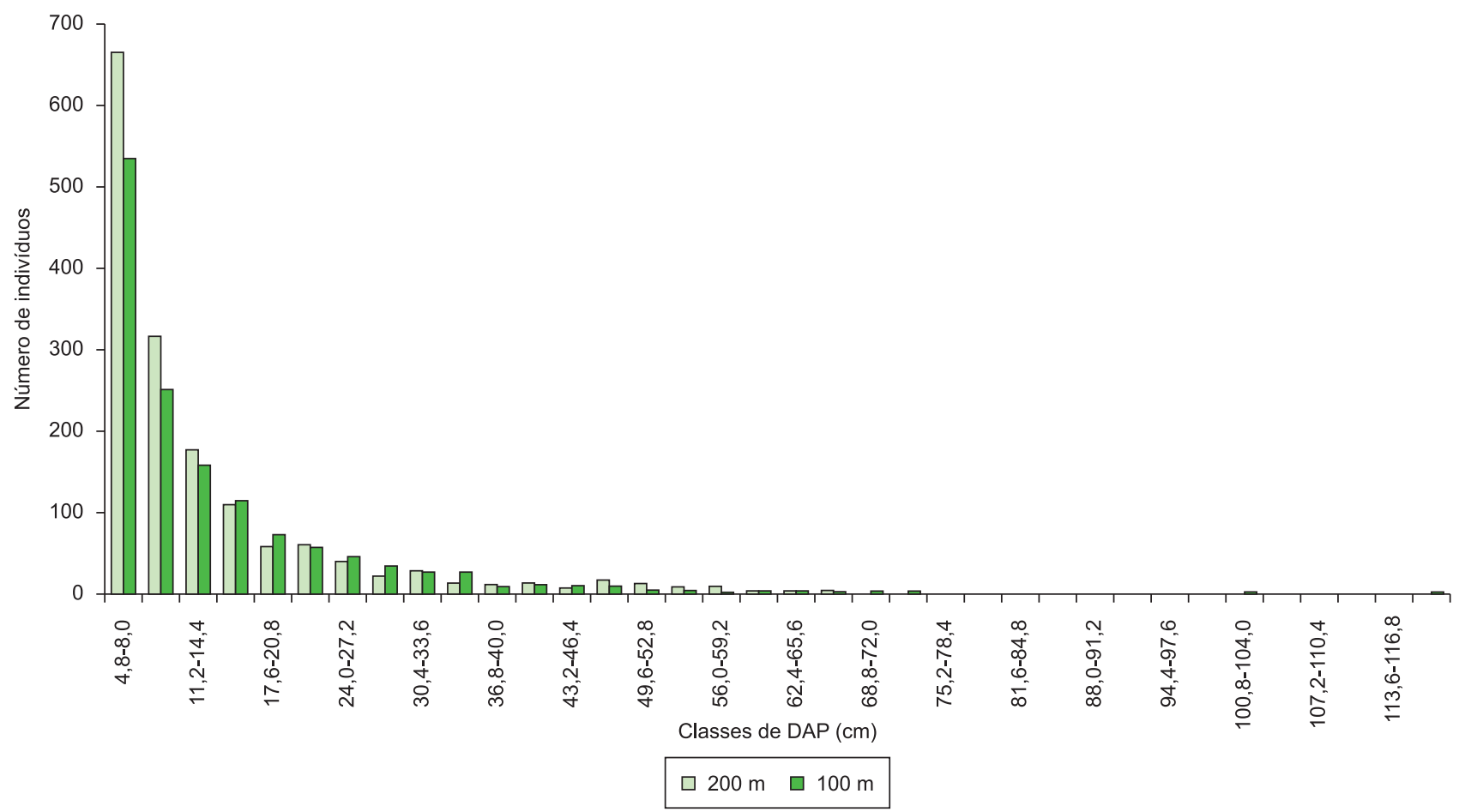

Figura 3. Classes de diâmeto à altura do peito (DAP) dos indivíduos com pelo menos $15 \mathrm{~cm}$ de perímetro de tronco (a 1,30 m do solo) amostrados em dois trechos de Floresta Ombrófila Densa Submonana (100 e 200 m de altitude) na Fazenda Capricórnio (Ubatuba, SP).

Figure 3. Diameter breast height (DBH) classes of individuals with at least $15 \mathrm{~cm}$ perimeter $(1,30 \mathrm{~m}$ beyond ground) sampled in two areas of Submontane Rainforest (at 100 and 200 m altitud) in Capricórnio Farm (Ubatuba, SP).

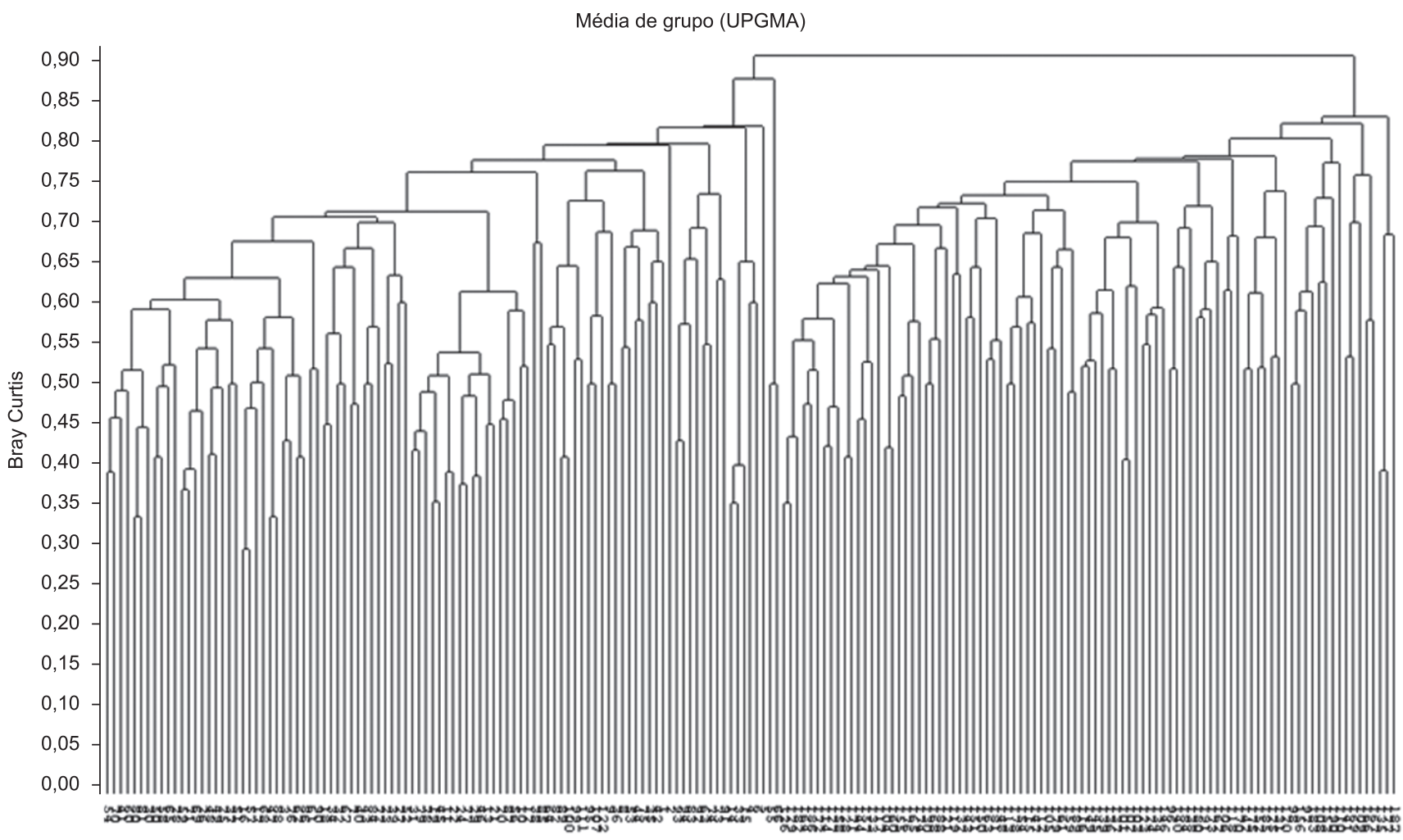

Figura 4. Dendrograma de similaridade (média de grupo UPGMA) calculada a partir da abundância de espécies amostradas em dois trechos de Floresta Ombrófila Densa Submonana (100 e 200 m de altitude) na Fazenda Capricórnio (Ubatuba, SP) em dois trechos de floresta ombrófila densa submontana, Ubatuba, SP através do índice de similaridade florística de Bray Curtis.

Figure 4. Dendrogram obtained by UPGMA, using the 'Bray Curtis' index, calculated from the species' ausence/presence sampled in two areas of Submontane Rainforest (at 100 and $200 \mathrm{~m}$ altitud) in Capricórnio Farm (Ubatuba, SP). 
à extinção (Schneider et al. 2003, Olifiers \& Cerqueira 2006), uma possível explicação para a menor riqueza na parcela $\mathrm{F}$ seria a perturbação da área.

As famílias Myrtaceae e Rubiaceae predominaram tanto em riqueza quanto em abundância nos dois trechos. Reconhecidamente ricas, estas famílias se destacam também em outros estudos realizados em áreas de mesma fisionomia (Silva \& Leitão Filho 1982, Sanchez et al. 1999, Lacerda 2001, Campos 2008).

Baixos valores de área basal foram associados, por diversos autores, a atividades como lavoura e pastagem (Guedes-Bruni et al. 2006), perturbações antrópicas e incêndios (Pessoa \& Oliveira 2006), redução de área e alteração na forma do fragmento (Silva \& Nascimento 2001), enquanto valores mais altos foram relacionados a um melhor estado de conservação (Kurtz \& Araújo 2000, Sztutman \& Rodrigues 2002, Moreno et al. 2003). Borém \& Oliveira-Filho (2002) encontraram diferenças que variavam do trecho mais perturbado para o mais conservado. Comparada aos valores obtidos em todos aqueles trabalhos, e conhecendo o histórico de exploração seletiva de madeira na Fazenda Capricórnio, o valor de área basal encontrado para a parcela $\mathrm{F}$ deve estar relacionado às interferências decorrentes da retirada de árvores. No entanto, este valor é maior que o encontrado para trechos de florestas mais perturbados, como por exemplo os trabalhos anteriormente citados. Na parcela $\mathrm{H}$ os valores aproximam-se dos observados em áreas mais bem conservadas. Comparações como essas devem ser consideradas com cautela, pois as diferenças na metodologia utilizada influenciam nos resultados.

$\mathrm{Na}$ parcela $\mathrm{F}$ a importância das espécies tem a ver com sua abundância, enquanto na parcela $\mathrm{H}$ este fator deve-se ao diâmetro dos indivíduos. Segundo Whitmore (1990), distúrbios ambientais como desmatamento e corte seletivo contribuem, em florestas tropicais de grande heterogeneidade florística, para o aumento da densidade de poucas espécies, o que deve explicar a situação da parcela $\mathrm{F}$, onde a extração seletiva de madeira pode ter proporcionado, além do aumento da densidade de B. australis, A. sternbergii e L. cultratus, certa perda de diversidade no estrato arbóreo. A grande abundância destas espécies deve ser favorecida pelas aberturas no dossel provocadas pela retirada das grandes árvores. $\mathrm{Na}$ parcela $\mathrm{H}$, que possui menor quantidade de clareiras, estas não se sobressaem tanto ou ocorrem com número bem menos expressivo de indivíduos, sendo pouco abundantes e até consideradas raras em outros trabalhos (Tabela 1).

Euterpe edulis, uma das espécies mais importantes da Mata Atlântica, foi intensamente explorada na parcela F, contrastando com o maior número de indivíduos ocorrentes na parcela H. Borém \& Ramos (2001) e Borém \& Oliveira-Filho (2002) associaram a abudância de E. edulis a áreas pouco alteradas. Lacerda (2001) também encontrou abundância de E. edulis em seu estudo, apesar das diferenças no tamanho das suas áreas de amostragem em relação ao presente estudo. Silva \& Leitão Filho (1982) e Moreno et al. (2003) encontraram pouca abundância para esta espécie, no entanto deve-se considerar que o critério de inclusão adotado naqueles trabalhos (DAP $\geq 10 \mathrm{~cm}$ ) foi maior que o considerado neste estudo. Já Cyatheaceae ocorre com maior abundância na parcela $\mathrm{F}$, e com poucos indivíduos na parcela $\mathrm{H}$, o que pode estar associado à diminuição do número de indivíduos de E. edulis, retirados clandestinamente. Além disso, o processo de retirada seletiva de madeira, que acaba por derrubar as árvores próximas às selecionadas para o corte, contribui para a formação de clareiras, que pode estar facilitando o estabelecimento das samambaias e dificultando a regeneração da população de palmitos nesta área. Segundo Nakazono et al. (2001), plantas de E. edulis apresentam intolerância à luz solar plena durante o seu crescimento inicial, sendo necessário certo grau de sombreamento neste estágio. Embora uma relação entre a ausência de E. edulis e a presença de

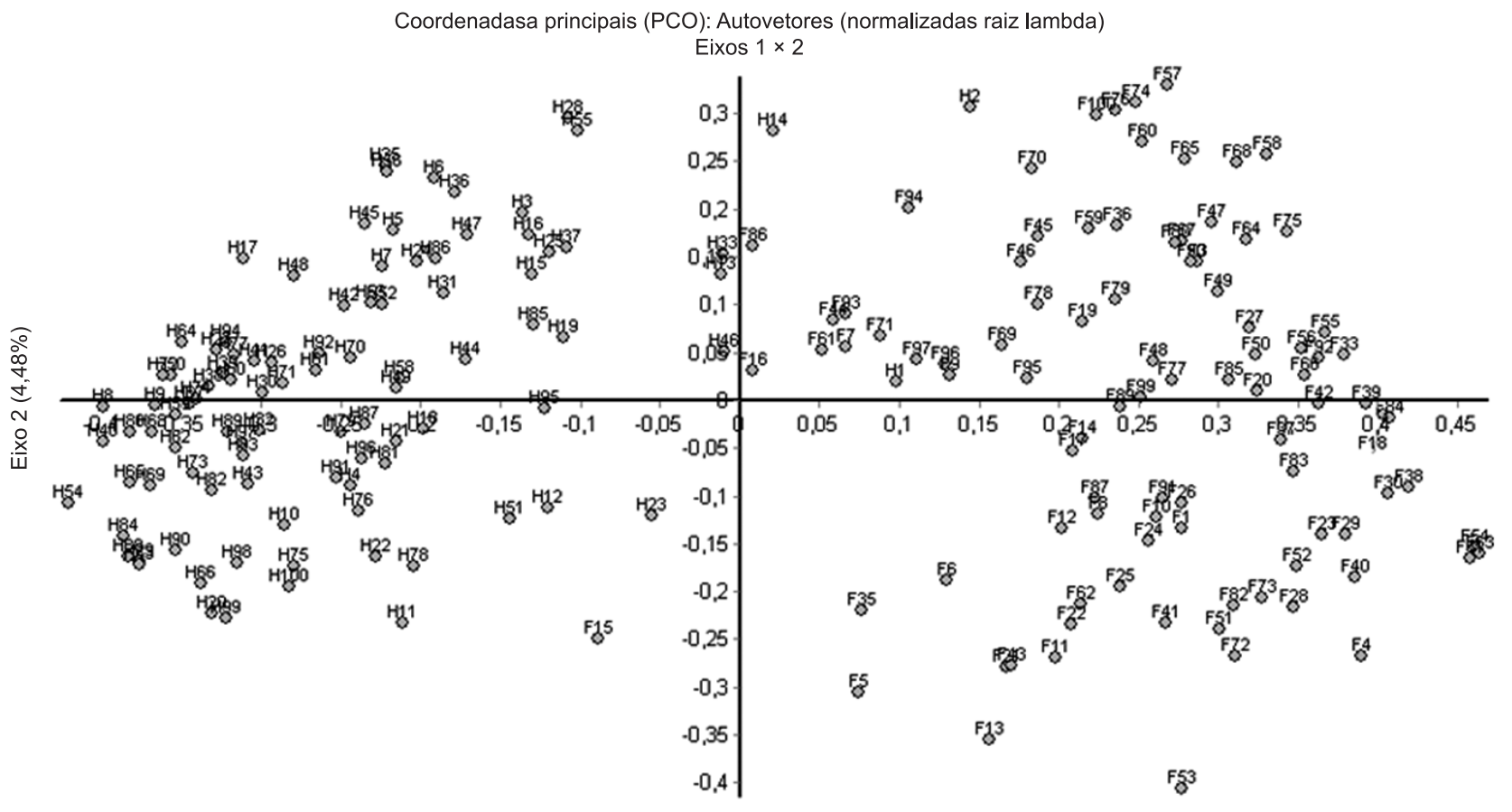

Eixo $1(14,34 \%)$

Figura 5. Diagrama de ordenação de uma Análise de Componentes (CA) calculados a partir da abundância de espécies amostradas em dois trechos de Floresta Ombrófila Densa Submonana (100 e 200 m de altitude) na Fazenda Capricórnio (Ubatuba, SP), através do índice de similaridade florística de Bray Curtis.

Figure 5. Ordination diagram of a CA calculated from the species' abundance sampled in two areas of Submontane Rainforest (at 100 and $200 \mathrm{~m}$ altitud) in Capricórnio Farm (Ubatuba, SP), using the Bray Curtis' floristic similarity index. 
A. sternbergii seja de difícil comprovação, é possível que estas espécies, que compartilham características arquiteturais semelhantes, se sobreponham parcialmente em relação ao nicho ocupado (Simey Fish, informação pessoal). Na parcela $\mathrm{H}$, A. sternbergii parece tolerar a luz e coloniza a área, tendo benefício frente a baixa abundância de E. edulis. Sylvestre \& Kurtz (1994) salientam a importância fitossociológica de Cyathea delgadii Sternb. em matas preservadas e em matas secundárias, devido aos seus consideráveis valores de densidade e frequiência. Melo \& Salino (2007) também observaram que A. sternbergii ocorria, com freqüência, em ambientes alterados. Schmitt \& Windisch (2007) observaram que indivíduos jovens de C. delgadii ocorriam em uma área cujo estágio sucessional era mais recente, com maior disponibilidade de luz no sub-bosque. O destaque de Cyatheaceae e a falta de E. edulis na parcela F sinalizam para a ocorrência de fatores de perturbação na área, dadas as características sucessionais dessas espécies.

Além da presença e principalmente da abundância de $A$. sternbergii e L. cultratus na parcela F, pode-se citar Cyathea hirsuta, Alchornea triplinervea, A. glandulosa e Cecropia glaziovii, que não estão presentes ou ocorrem com número bem menor de indivíduos na parcela $H$. Provavelmente as perturbações ocorridas no primeiro trecho favoreceram o estabelecimento destas espécies por tornar o ambiente mais aberto. Borém \& Oliveira-Filho (2002) atribuíram a abundância de espécies como Cecropia glaziovii à perturbação ocorrida na área estudada por eles, chamando a atenção para o fato de a espécie ser indicadora de formações que sofreram alterações.

Enquanto $62 \%$ das espécies ocorrentes na parcelas $\mathrm{F}$ são pioneiras ou secundárias iniciais, na parcela $\mathrm{H}$ as espécies destas categorias sucessionais atingem $18 \%$ (Tabela 1). Já para as espécies clímax ou secundárias tardias, acontece o contrário: $22 \%$ ocorrem na parcela $\mathrm{F}$ e $65 \%$ na parcela $\mathrm{H}$, sendo este outro indicador das diferenças de conservação entre as áreas.

Baixos índices de diversidade são associados a perturbações antrópicas (Borém \& Oliveira-Filho 2002), o que corresponde às condições da parcela F. Provavelmente a maior perturbação deste ambiente, decorrente da extração seletiva de madeira e palmito, contribuiu para as diferenças encontradas. Os valores obtidos para a parcela F são menores que os de trechos conservados de Floresta Ombrófila Densa Submontana, enquanto os da parcela H são equivalentes ou um pouco menores, quando comparados a outros trabalhos (Lacerda 2001, Guedes-Bruni et al. 2006, Carvalho et al. 2007).

Em análise de Pedro Eisenlohr (comunicação pessoal), a parcela $\mathrm{F}$ apresentou diferenças florísticas tanto em relação à parcela $\mathrm{H}$ quanto às outras cinco parcelas analisadas ao longo do gradiente altitudinal, e não houve influência do aumento de altitude na riqueza e diversidade de espécies. Assim, pode-se sugerir que, embora localizados em altitudes diferentes, grande parte das diferenças entre os dois trechos aqui estudados pode ser atribuída à perturbação antrópica.

A formação de blocos e grupos florísticos distintos para os dois trechos estudados é corroborada pela convergência entre os resultados gerados a partir das duas matrizes florísticas, porém a maior consistência na ordenação por PCO da matriz quantitativa sugere que a abundância dos indivíduos é um fator bem importante na separação dos blocos e, aliada às diferenças quanto à área basal, o histórico de perturbação deve ser levado em consideração nos resultados, que indicam que os trechos estudados apresentam diferenças estruturais.

Com relação à distribuição geográfica das espécies ou a sua classificação sucessional, houve dificuldades de se obter informações para todos os táxons. Essas informações geralmente foram encontradas em trabalhos de flora e monografias. A presença de espécies com baixa constância é um fato comum na Mata Atlântica (Scudeller 2001), o que contribui para a diversidade das áreas estudadas. Caiafa \& Martins (2010) salientam que variáveis como a presença de espécies raras em diferentes graus, distribuição geográfica restrita, restrição de hábitats e baixa abundância local demonstram a situação de ameaça à qual as espécies da Mata Atlântica estão sujeitas. Embora aqueles autores tenham utilizado uma metologia diferente e uma área bem mais abragente para aplicar os critérios sugeridos por Rabinowitz et al. (1986), esta afirmação também se aplica ao presente estudo, onde foram encontradas muitas espécies raras e que só ocorrem em ambientes de Floresta Ombrófila Densa, considerando-se no presente estudo esta fisionomia como variável de distribuição restrita. 'Uma vez que a conservação in situ é considerada a melhor estratégia para a proteção de espécies ameaçadas, destaca-se a grande importância do Parque Estadual da Serra do Mar, que abriga extensas áreas de floresta ainda preservada.

\section{Conclusões}

Os resultados confirmam que os trechos estudados diferem entre si em sua composição, diversidade, estrutura e prevalência das categorias sucessionais das espécies. As características distintas entre os dois trechos indicam condições diferentes de conservação, sendo a parcela $\mathrm{H}$ menos perturbada. As diferenças florísticas e estruturais constatadas entre os dois trechos podem ser associadas principalmente à ocorrência e à intensidade das perturbações sofridas pela parcela F. Para as duas áreas, as espécies amostradas são as comumente descritas para a fisionomia da Floresta Ombrófila Densa Submontana, e as famílias mais ricas são, exceto Cyatheaceae, aquelas comumente citadas em trabalhos realizados em outros trechos de mesma fisionomia. A presença de espécies com diferentes graus de raridade e endemismo indica a importância da área e a situação de ameaça das espécies aí ocorrentes.

\section{Agradecimentos}

Este trabalho é parte da dissertação de Mestrado da primeira autora. Programa de Pós Graduação em Agricultura Tropical e Subtropical, Instituto Agronômico, Campinas-SP, e foi parcialmente financiado pela Fundação de Amparo à Pesquisa do Estado de São Paulo (FAPESP) no âmbito do Projeto Temático Biota Gradiente Funcional: Composição florística, estrutura e funcionamento da Floresta Ombrófila Densa dos Núcleos Picinguaba e Santa Virgínia do Parque Estadual da Serra do Mar (Processo 03/12595-7), que faz parte do Programa BIOTA/FAPESP - O Instituto Virtual da Biodiversidade (www.biota.org.br). Autorização COTEC/IF 41.065/2005 e autorização IBAMA/CGEN 093/2005. Os autores agradecem: a Fapesp pela infra-estrutura disponibilizada no projeto temático; aos proprietários da Fazenda Capricórnio, por autorizarem a realização do trabalho na área; às Dras. Simone Aparecida Vieira e Luciane F. Alves, pela coordenação dos trabalhos de campo; aos srs. Salvador dos Santos e Osvaldo dos Santos, José Ataliba Mantelli Aboin Gomes, Fábio Benedetti e Hugo Rodrigues Gonçalves pelo auxílio nos trabalhos de campo; José Ataliba Mantelli Aboin Gomes, George J. Shepherd, Juliano Van Melis e Catia Urbanetz pelo auxílio com o programa Fitopac; Adriana Ramos pelo auxílio com as figuras; Mariella Eltink (IAC) pelo grande auxílio no processamento dos materiais coletados e na elaboração das fotos; Ariane Saldanha de Oliveira (IAC) pelo processamento dos materiais coletados; Leonardo Dias Meireles, Luis Carlos Bernacci, Marco Assis, João Semir, Jorge Yoshio Tamashiro pelo auxílio na triagem e identificação das espécies; Angela Borges Martins (Melastomataceae), Cyl Farney (Nyctaginaceae), Edson Dias da Silva (Fabaceae), Fátima O. Souza (Asteraceae), Giseli Areias (Cyatheaceae), Inês Cordeiro (Euphorbiaceae), João Batista Baitello (Lauraceae), Luis Carlos Bernacci (Myrsinaceae), Marcos Guerra Sobral (Myrtaceae), Sérgio Romaniuc Neto (Moraceae e Urticaceae) 
e Sigrid Luiza Jung Mendaçolli (Rubiaceae) pela identificação ou confirmação das determinações; Pedro Vasconcellos Eisenlohr, pela inestimável ajuda com as análises.

\section{Referências Bibliográficas}

BARBOSA, L.M., BARBOSA, T.C., BARBOSA, K.C., PARAJARA, F.C., BARBOSA, J.M. \& SHIRASUNA, R. 2009. A importância dos estudos sobre a flora e a restauração florestal, nas áreas diretamente afetadas do Rodoanel Trecho Sul em São Paulo - SP. In: Anais do III Simpósio sobre Recupração de Áreas Degradadas. L.M. Barbosa (coord.). SMA, IB, p. 10-39.

BERNACCI, L.C., FRANCO, G.A.D.C., ÀRBOCZ, G.F., CATHARINO, E.L.M., DURIGAN, G. \& METZGER, J.P. 2006. O efeito da fragmentação florestal na composição e riqueza de árvores na região da Reserva Morro Grande (Planalto de Ibiúna, SP). Rev. Inst. Flor. 18:121-166.

BIODIVERSITAS. 2010. Revisão da lista da flora brasileira amaeaçada de extinção. http://www.biodiversitas.org.br

BORÉM, R.A.T. \& OLIVEIRA-FILHO, A.T. 2002. Fitossociologia do estrato arbóreo em uma topossequência alterada de Mata Atlântica, no município de Silva Jardim - RJ, Brasil. Rev. Arvore 26(6):727-742.

BORÉM, R.A.T. \& RAMOS, D.P. 2001. Estrutura fitossociológica da comunidade arbórea de uma topossequência pouco alterada de uma área de floresta atlântica, no município de Silva Jardim-RJ. Rev. Arvore 25(1):131-140.

BRANDÃO, C.F.L.S., MARANGON, L.C., FERREIRA, R.L.C. \& LINS E SILVA, A.C. 2009. Estrutura fitossociológica e classificação sucessional do componente arbóreo em um fragmento de floresta atlântica em Igarassu - Pernambuco. Rev. Bras. Ciênc. Agrár. 4(1):55-61.

BRASIL. 2008. Ministério do Meio Ambiente - MMA. Instrução normativa MMA n 06, de 23 de setembro de 2008. Disponível em: http://www. mma.gov.br/sitio/index.php?ido=conteudo.monta\&idEstrutura $=179 \&$ id Conteudo $=8121 \&$ idMenu $=8618$

CAIAFA, A.N. \& MARTINS, F.R. 2010. Forms of rarity of tree species in the southern Brazilian Atlantic rainforest Biodivers. Conserv. 19:25972618. http://dx.doi.org/10.1007/s10531-010-9861-6

CAMPOS, M.C.R. 2008. Relação da composição e estrutura do componente arbóreo com variáveis micropográficas e edáficas da Floresta Ombrófila Densa do Núcleo Picinguaba/PESM, Ubatuba/SP. Dissertação de Mestrado, Universidade Estadual de Campinas, Campinas.

CARDOSO-LEITE, E. \& RODRIGUES, R.R. 2008. Fitossociologia e caracterização sucessional de um fragmento de floresta estacional no Sudeste do Brasil. Rev. Arvore 32(3):583-595. http://dx.doi.org/10.1590/ S0100-67622008000300019

CARVAlHO, F.A., NASCimento, M.T. \& BRAGA, M.A. 2006. Composição e riqueza florística do componente arbóreo da Floresta Atlântica submontana na região de Imbaú, Município de Silva Jardim, RJ. Acta Bot. Bras. 20(3):727-740. http://dx.doi.org/10.1590/S010233062006000300022

CARVALHO, F.A., NASCIMENTO, M.T. \& BRAGA, M.A. 2007. Estrutura e composição florística do estrato arbóreo de um remanescente de Mata Atlântica submontana no município de Rio Bonito, RJ, Brasil (Mata Rio Vermelho). Rev. Arvore 31(4):717-730. http://dx.doi.org/10.1590/ S0100-67622007000400017

CATHARINO, E.L.M., BERNACCI, L.C., FRANCO, G.A.D.C., DURIGAN, G. \& METZGER, J.P. 2006. Aspectos da composição e diversidade do componente arbóreo das florestas da Reserva Florestal do Morro Grande, Cotia, SP. Biota Neotrop. 6(2):1-28. http://dx.doi.org/10.1590/S167606032006000200004

DIAS NETO, O.C., SCHIAVINI, I., LOPES, S.F., VALE, V.S., GUSSON, A.E. \& OLIVEIRA, A.P. 2009. Estrutura fitossociológica e grupos ecológicos em fragmento de floresta estacional semidecidual, Uberaba, Minas Gerais, Brasil. Rodriguésia 60(4):1087-1100.

ELTINK, M., RAMOS, E., TORRES, R.B., TAMASHIRO, J.Y., GALLEMBECK, E. \& KIMURA, E. 2011. Chave de identificação de espécies do componente arbóreo da Floresta Ombrófila Densa Atlântica Submontana do Núcleo Picinguaba/PESM, Ubatuba/ SP, com base em caracteres vegetativos. Biota Neotropica 11(2): http://www.biotaneotropica.org.br/v11n2/pt/abstract?identificationkey+bn02511022011
ELTINK, M., TORRES, R.B., RAMOS, E., GALEMBECK, E. \& KIMURA, E. 2009. Guia de árvores da Mata Atlântica. UNICAMP, Campinas. http://www.bdc.ib.unicamp.br/gama

FOOD AND AGRICULTURE ORGANIZATION - FAO. 2006. Global Forest Resources Assessment 2005. Progress towards sustainable forest management. FAO Forestry Paper 147.

FORZZA, R.C., LEITMAN, P.M., COSTA, A., CARVALHO JR, A.A. PEIXOTO, A.L., WALTER, B.M.T., BICUDO, C., ZAPPIR, D., COSTA, D.P., LlerAS, E., MARTINELli, G., LiMA, H.C., PRADO, J. STEHMANN, J.R., BRAUMGRATZ, J.F.A., PIRANI, J.R., SYLVESTRE, L.S., MAIA, L.C., LOHMANN, L.G., PAGANUCCI, L., SILVEIRA, M., NADRUZ, M., MAMEDE, M.C.H., BASTOS, M.N.C., MORIM, M.P., BARBOSA, M.R., MENEZES, M., HOPKINS, M., SECCO, R. CAVALCANTI, T., SOUZA, V.C. 2010. Lista de Espécies da Flora do Brasil. Jardim Botânico do Rio de Janeiro. Disponível em: http://floradobrasil.jbrj.gov.br/2010

GALINDO-LEAL, C. \& CÂMARA, I.G. 2005. Status do hotspot Mata Atlântica: uma síntese. In Mata Atlântica: biodiversidade, ameaças e perspectivas (C. Galindo-Leal \& I.G. Câmara, eds.). Fundação SOS Mata Atlântica, p.3-11. http://www.conservation.org.br/publicacoes/ files/CapituloIStatusdoHotspotMataAtlantica.pdf (último acesso em 20/10/2010.).

GAUCH JUNIOR, H.G. 1982. Multivariate analysis in community ecology. Cambridge Studies in Ecology, Cambridge.

GUEDES-BRUNI, R.R., SILVA NETO, S.J., MORIM, M.P.\& MANTOVANI, V. 2006. Composição florística e estrutura de trecho de floresta ombrófila densa atlântica aluvial na Reserva Biológica de Poço das Antas, Silva Jardim, Rio de Janeiro, Brasil. Rodriguésia 57(3):413-428.

HAMMER, Ø., HARPER, D.A.T. \& RYAN, P.D. 2001. PAST Palaeontological statistics. http://folk.uio.no/ohammer/past/ (último acesso em 12/02/2009).

HEGERL, G.C., ZWIERS, F.W., BRACONNOT, P., GILLET, N.P., LUO, Y., MARENGO ORSINI, J.A., NICHOLLS, N., PENNER, J.E. \& STOTT, P.A. 2007. 2007: Understanding and attributing climate change. In Climate Change 2007: The Physical Science Basis. Contribution of Working Group I to the Fourth Assessment Report of the Intergovernmental Panel on Climate Change (S. Solomon, D. Qin, M. Manning, Z. Chen, M. Marquis, K.B. Averyt, M. Tignor, \& H.L. Miller, eds). Cambridge University Press, Cambridge, United Kingdom and New York, p.663-745. http://www.ipcc.ch/pdf/assessment-report/ar4/wg3/ ar4-wg3-chapter9.pdf. (último acesso em 17/01/2008).

HERO, J.-M. \& RIDGWAY, T. 2006. Declínio global de espécies. In Biologia da Conservação: Essências (C.F.D. Rocha, H.G. Bergallo, M.V. Sluys \& M.A.S. Alves, orgs). Rima, São Carlos, p.53-90.

INSTITUTO FLORESTAL - IF. 2006. Plano de manejo do Parque Estadual da Serra do Mar. Instituto Florestal, Instituto Ekos Brasil, São Paulo. http://www.iflorestal.sp.gov.br/Plano_de_manejo/PE_SERRA_MAR. (último acesso em 22/01/2008).

IVANAUSKAS, N.M. 1997. Caracterização florística e fisionômica da Floresta Atlântica sobre a formação Pariquera-Açu, na Zona da Morraria Costeira do estado de São Paulo. Dissertação de Mestrado, Instituto de Biologia, Universidade Estadual de Campinas, Campinas.

JENKINS, C.N. \& PIMM, S.L. 2006. Definindo prioridades de conservação em um hotspot de biodiversidade global. In Biologia da Conservação: Essências (C.F.D. Rocha, H.G. Bergallo, M.V. Sluys \& M.A.S. Alves, orgs). RiMa, São Carlos, p.41-52.

JOLY, C.A., ASSIS, M.A., BERNACCI, L.C., TAMASHIRO, J.Y., CAMPOS, M.C.R., GOMES, J.A.M.A., SANCHEZ, M., SANTOS, F.A.M., PEDRONI, F., PEREIRA, L.S., PADGURSCHI, M.C., PRATA, E.M.B., RAMOS, E., TORRES, R.B., ROCHELLE, A.L.C., MARTINS, F.R, ALVES, L.F., VIEIRA, S.A., MARTINELLI, L.A., CAMARGO, P.B., SIMÕES, E., VILLANI, J.P. \& BELINELLO, R. 2011. Florística e fitossociologia do componente arbóreo da Mata Atlântica ao longo do gradiente altitudinal dos Núcleos Picinguaba e Santa Virgínia/PESM, do sudeste do Brasil. Biota Neotropica 11(2):no prelo.

KRONKA, F.J.N., NALON, M.A. \& MATSUKUMA, C.K. (coord). 2005. Inventário florestal da vegetação natural do Estado de São Paulo. Secretaria de Meio Ambiente, Instituto Florestal e Imprensa Oficial, São Paulo. 
KURTZ, B.C. \& ARAÚJO, D.S.D. 2000. Composição florística e estrutura do componente arbóreo de um trecho de Mata Atlântica na Estação Ecológica Estadual do Paraíso, Cachoeiras de Macacu, Rio de Janeiro, Brasil. Rodriguésia 51(78/79):69-111.

LACERDA, M.S. 2001. Composição florística e estrutura da comunidade arbórea num gradiente altitudinal da Mata Atlântica. Tese de Doutorado, Universidade Estadual de Campinas, Campinas.

MAGURRAN, A.E. 2004. Measuring Biological Diversity. Blackwell Publishing, Oxford.

MANTOVANI, M., RUSCHEL, A.R., PUCHALSKI, A., SILVA, J.Z., REIS, M.S. \& NODARI, R.O. 2005. Diversidade de espécies e estrutura sucessional de uma formação secundária da floresta ombrófila densa. Sci. For. 67:14-26.

McCUNE, B. \& MEFFORD, M.J. 1999. PC-ORD - multivariate analysis of ecological data, version 4.0. MjM Software Design, Gleneden Beach.

MELO, L.C.N. \& SALINO A. 2007. Pteridófitas em fragmentos florestais da APA Fernão Dias, Minas Gerais, Brasil. Rodriguésia 58(1):207-220.

MOREIRA, C.M. 2007. Avaliação de métodos fitossociológicos através de simulações de amostragens numa parcela permanente de Cerradão, na Estção Ecológica de Assis, SP. Dissertação de Mestrado, Escola Superior de Agricultura Luiz de Queiroz, Piracicaba.

MORENO, M.R., NASCIMENTO, M.T. \& KURTZ, B.C. 2003. Estrutura e composição florística do estrato arbóreo em duas zonas altitudinais na Mata Atlântica de encosta da região de Imbé, RJ. Acta Bot. Bras. 17(3):371-386.

MYERS, N., MITTERMEIER, R.A., MITTERMEIER, C.G., FONSECA, G.A.B. \& KENT, J. 2000. Biodiversity hotspots for conservation priorities. 2000. Nature 403:852-858. http://dx.doi.org/10.1038/35002501

NAKAZONO, E.M., COSTA, M.C., FUTATSUGI, K. \& PAULILO, M.T.S 2001. Crescimento inicial de Euterpe edulis Mart. em diferentes regimes de luz. Rev. Bras. Bot. 24(2):173-179. http://dx.doi.org/10.1590/S010084042001000200007

NEVES, G.M.S. \& PEIXOTO, A.L. 2008. Florística e estrutura da comunidade arbustivo-arbórea de dois remanescentes em regeneração de Floresta Atlântica secundária na Reserva Biológica de Poço das Antas, Silva Jardim, Rio de Janeiro. Pesq., Bot. 59:71-112.

OLIFIERS, N. \& CERQUEIRA, R. 2006. Fragmentação de habitat: efeitos históricos e ecológicos. In Biologia da conservação: essências (C.F.D. Rocha, H.G. Bergallo, M.V. Sluys \& M.A.S. Alves, orgs.). RiMa, São Carlos, p. 261-279.

PESSOA, S.V.A. \& OLIVEIRA, R.R. 2006. Análise estrutural da vegetação arbórea em três fragmentos florestais na Reserva Biológica de Poços das Antas, Rio de Janeiro, Brasil. Rodriguésia 57(3):391-411.

PIELOU, E.C. 1975. Ecological Diversity. John Wiley and Sons, New York.

PINTO, L.V.A., DAVIDE, A.C., BOTELHO, S.A., OLIVEIRA-FILHO, A.T. \& MACHADO, E.L.M. 2005. Distribuição das espécies arbóreoarbustivas ao longo do gradiente de umidade do solo de nascentes pontuais da bacia hidrográfica do Ribeirão Santa Cruz, Lavras, MG. Cerne 11(3):294-305.

POOLE, R.W. 1974. An introduction to quantitative ecology. McGraw-Hill, New York.

RABINOWITZ, D., CAIRNS, S. \& DILLON, T. 1986. Seven forms of rarity and their frequency in the flora of the British Isles. In Conservation biology: the science of scarcity and diversity (M.E. Soulé, ed.). Sinauer Associates, Massachusetts, p.95-114.

RANGEL, M.S., CALEGARIO, N., MELLO, A.A., \& LEMOS, P.C. 2006 Melhoria na precisão da prescrição de manejo para floresta natural. Cerne 12(2):145-156.

REITZ, R. 1974. Palmeiras. In Flora Ilustrada Catarinense. (R. Reitz, ed). Herbário Barbosa Rodrigues, Itajaí, Fascículo Palm, p. 1-189.

SANCHEZ, M., PEDRONI, F., LEITÃO FILHO, H.F. \& CÉSAR, O. 1999. Composição florística de um trecho de floresta ripária na Mata Atlântica em Picinguaba, Ubatuba, SP. Rev. Bras. Bot. 22(1):31-42. http://dx.doi. org/10.1590/S0100-84041999000100006
SANTOS, F.V., SOLÓRZANO, A., GUEDES-BRUNI, R.R. \& OLIVEIRA, R.R. 2006. Composição do estrato arbóreo de um paleoterritório de carvoeiros no maciço da Pedra Branca, RJ. Pesq., Bot. 57:181-192.

SÃO PAULO (Estado). 2008. Secretaria de Estado do Meio Ambiente - SMA. Listagem das espécies arbóreas e indicação de sua ocorrência natural nos biomas/ecossistemas e regiões ecológicas do Estado de São Paulo, com a classificação sucessional e a categoria de ameaça de extinção. http://www.ibot.sp.gov.br/pesquisa_cientifica/restaracao_ecologica/ anexo_resol_sma-08-08.pdf. (último acesso em 14/11/2010).

SCHMITT, J.L. \& WINDISCH, P.G. 2007. Estrutura populacional e desenvolvimento da fase esporofítica de Cyathea delgadii Sternb. (Cyatheaceae, Monilophyta) no sul do Brasil. Acta Bot. Bras. 21(3):731-740. http://dx.doi.org/10.1590/S0102-33062007000300019

SCHNEIDER, M.P.C., BATISTA, C.G., CARVALHO, D., CERQUEIRA, R., CIAMPI, A.N., FRANCESCHINELLI, E.V., GENTILE, R., GONÇALVES, E.C., GRATIVOL, A.D., NASCIMENTO, M.T., PÓVOA, J.R., VASCONCELOS, G.M.P., WADT, L.H. \& WIEDERHECKER, H.C. 2003. Genética de populações naturais. In Fragmentação de ecossistemas: causas, efeitos sobre a biodiversidade e recomendações de políticas públicas (D.M. Rambaldi \& D.A.S. Oliveira, orgs.). MMA, SBF, Brasília, p.297-315.

SCHORN, L.A. \& GALVÃO, F. 2006. Dinâmica da regeneração natural em três estágios sucessionais de uma floresta ombrófila densa em Blumenau, SC. Floresta 36(1): 59-74.

SCUDELLER, V.V., MARTINS, F.R. \& SHEPHERD, G.J. 2001. Distribution and abundance of arboreal species in the atlantic ombrophilous dense forest in Southeastern Brazil. Plant Ecol. 152:185-199.

SEOANE, C.E.S., KAGEYAMA, P.Y. \& SEBBENN, A.M. 2000. Efeitos da fragmentação florestal na estrutura genética de populações de Esenbeckia leiocarpa Engl. (guarantã). Sci. For. 57:123-139.

SHEPHERD, G.J. 2009. FITOPAC 2.1 (versão preliminar). Departamento de Biologia Vegetal, Universidade Estadual de Campinas.

SILVA, A.F. \& LEITÃO FILHO, H.F. 1982. Composição florística e estrutura de um trecho de Mata Atlântica de encosta no Município de Ubatuba (São Paulo, Brasil). Rev. Bras. Bot. 5(1/2):43-52.

SILVA, G.C. \& NASCIMENTO, M.T. 2001. Fitossociologia de mata sobre tabuleiros no norte do estado do Rio de Janeiro (Mata do Carvão). Rev. Bras. Bot. 24(1):51-62. http://dx.doi.org/10.1590/S010084042001000100006

SILVA, J.M.C. \& CASTELETI, C.H. 2005. Estado da biodiversidade da Mata Atlântica brasileira. In Mata Atlântica: biodiversidade, ameaças e perspectivas (C. Galindo-Leal \& I.G. Câmara, eds). Fundação SOS Mata Atlântica, p.43-59. http://www.conservation.org.br/publicacoes/ files/CapituloVEstadodabiodiversidadedaMataAtlanticabrasileira.pdf (último acesso em 20/10/2010.).

SNEATH, P.H. \& SOKAL, R.R. 1973. Numerical taxonomy. Freeman and Company, San Francisco.

SYLVESTRE, L.S. \& KURTZ, B.C. 1994. Cyatheaceae. In Reserva Ecológica de Macaé de Cima, Nova Friburgo-RJ. Aspectos florísticos das espécies vasculares. (M.P.M. Lima, \& R.R. Guedes-Bruni, orgs.). Ministério do Meio Ambiente e da Amazônia Legal/IBAMA/Jardim Botânico do Rio de Janeiro, Rio de Janeiro, v.1, p.139-152.

SZTUTMAN, M. \& RODRIGUES, R.R. 2002. O mosaico vegetacional numa área de floresta contínua da planície litorânea, Parque Estadual da Campina do Encantado, Pariquera-Açu, SP. Rev. Bras. Bot. 25(2):161-176. http://dx.doi.org/10.1590/S0100-84042002000200005

VELOSO, H.P., RANGEL FILHO, A.L.R. \& LIMA, J.C.A. 1991. Classificação da vegetação brasileira, adaptada a um sistema universal. IBGE, Rio de Janeiro.

WHITMORE, T.C. 1990. An introduction to tropical rain forests. Clarendon Press, Oxford.

ZAR, J.H. 1999. Biostatistical analysis. $4^{\text {nd }}$ ed. Prentice Hall, New Jersey. 